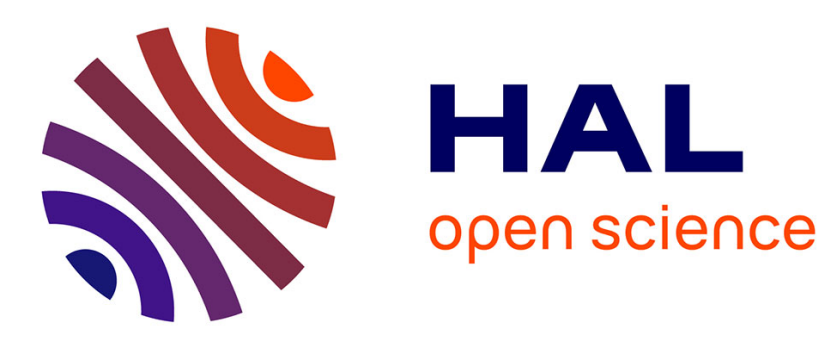

\title{
Cell-Specific Neuropharmacology
}

Sarah Mondoloni, Romain Durand-de Cuttoli, Alexandre Mourot

\section{To cite this version:}

Sarah Mondoloni, Romain Durand-de Cuttoli, Alexandre Mourot. Cell-Specific Neuropharmacology. Trends in Pharmacological Sciences, 2019, 40 (9), pp.696-710. 10.1016/j.tips.2019.07.007 . hal02344518

\section{HAL Id: hal-02344518 https: / hal.sorbonne-universite.fr/hal-02344518}

Submitted on 4 Nov 2019

HAL is a multi-disciplinary open access archive for the deposit and dissemination of scientific research documents, whether they are published or not. The documents may come from teaching and research institutions in France or abroad, or from public or private research centers.
L'archive ouverte pluridisciplinaire HAL, est destinée au dépôt et à la diffusion de documents scientifiques de niveau recherche, publiés ou non, émanant des établissements d'enseignement et de recherche français ou étrangers, des laboratoires publics ou privés. 


\section{Cell-specific neuropharmacology}

2

3 Sarah Mondoloni ${ }^{1^{*}}$, Romain Durand-de Cuttoli ${ }^{1,2^{*}}$ and Alexandre Mourot ${ }^{1^{*}}$

4

5

$6{ }^{1}$ Neuroscience Paris Seine - Institut de Biologie Paris Seine (NPS - IBPS), CNRS, INSERM,

7 Sorbonne Université, Paris, France

8

$9{ }^{2}$ Nash Family Department of Neuroscience, Center for Affective Neuroscience, and Friedman

Brain Institute, Icahn School of Medicine at Mount Sinai, New York, NY, USA

* All the authors contributed equally to the work

Correspondence : alexandre.mourot@upmc.fr (A. Mourot)

21 Key words: optogenetics, chemogenetics, tethered ligand, bump-hole, receptor-ligand pair, 22 photopharmacology 


\section{Abstract}

25

26 Neuronal communication involves a multitude of neurotransmitters and an outstanding

27 diversity of receptors and ion channels. Linking the activity of cell surface receptors and ion channels in defined neural circuits to brain states and behaviors has been a key challenge in neuroscience, since cell-targeting is not possible with traditional neuropharmacology. We review here recent technologies that enable the effect of drugs to be restricted to specific cell types, thereby allowing acute manipulation of the brain's own proteins with circuit specificity. We highlight the importance of developing cell-specific neuropharmacology strategies for

33 decoding the nervous system with molecular- and circuit-precision, and for developing future 34 therapeutics with reduced side effects. 
Investigating the function of neurotransmitter receptors and ion channels has greatly benefited from both pharmacological and genetic techniques. Conditional mutagenesis and virally-delivered shRNAs enable the manipulation of proteins with molecular specificity and in targeted brain circuits, notably through the use of cre/lox recombination. Yet, these techniques do not have sufficient temporal resolution to establish a direct link between the activation of receptors and the modulation of circuits and behavior. In addition, they can lead to developmental alterations that compensate for those induced by the deletion/mutation of the receptor. In contrast, conventional pharmacology offers acute and often reversible control of endogenous proteins, enables graded alterations by varying drug concentration, and can be applied at any time in development. Nevertheless, pharmacology suffers from lack of functional selectivity, since small chemicals affect all types of neurons cannot be cell-targeted. This is especially an issue considering the wide distribution of ion channels and receptors in the brain, and the various functions they have in different cells or networks. Local distribution of drugs to precise brain regions may afford anatomical specificity, but has major drawbacks, such as the difficulty to control dosage and diffusion, and the inability to target specific neuronal types. Making small chemicals photocontrollable using caged compounds or photoswitches permits cellular or even subcellular optical targeting at the single cell level, and improves spatio-temporal control in vivo [1,2]. Yet, even with the most sophisticated light source, controlling receptors located on different cell types within the same circuit in an intact brain is elusive with optical techniques alone. The ability to acutely control signaling proteins in a complex environment such as the nervous system in a cellular- and circuit-specific manner and in the behaving animal should accelerate progress in our molecular understanding of brain function (Figure 1A).

The idea behind cell-specific pharmacology is to combine the acute onset of pharmacology with the cellular and molecular precision of genetics, to achieve acute control of signaling proteins in a cell-specific fashion. To this aim, several chemogenetic strategies have recently been developed, which we classify here in three categories (Figure 1, key figure, Table 1). The receptor-ligand pair approach (Figure 1B) consists in re-engineering proteins to make them sensitive to synthetic ligands. The key outcome is an increase in potency of the synthetic ligand 
compared to the natural one (Figure 1C). The tethered-ligand approach (Figure 1D) relies on the anchoring of a ligand to the cell surface and results in an increased local concentration of the ligand. Anchoring can be performed either to a membrane-embedded element (membrane-tethered) or to a genetically-modified receptor (receptor-tethered). Finally, the last approach is to selectively deliver drugs to the cytoplasm of targeted cells, either using enzyme-prodrug pairs or facilitated diffusion through large ion channels (Figure 1E). Cellspecific neuropharmacology approaches provide the ability to test the function of receptors on specific types of neurons with unprecedented cellular precision (e.g. pre- vs. post-synaptic cells, or two different cell types within the same circuit) $[3,4]$. They also offer a unique opportunity to test the benefits of cell-targeted drugs for neurological and neuropsychiatric disorders. We review here these techniques, with a special focus on surface receptors and ion channels, highlighting their potentials and pitfalls, and the challenges they meet for in vivo use in rodents and for clinical applications.

\section{The receptor-ligand pair approach}

One central problem of traditional pharmacology is to identify small molecules that interact with a desired protein target with high specificity. This is especially challenging for proteins that belong to large protein families and therefore share a high degree of homology with other proteins in the cell. To address this shortcoming, a chemo-genetic strategy named bump-hole was developed, allowing inhibition of specific alleles of protein kinases [5]. The idea is to genetically create a hole on the catalytic active site of the protein, and to chemically modify the inhibitor, with a corresponding bump (Figure 1B). The synthetic ligand is orthogonal: it confers high specificity to the engineered enzyme, without affecting wild-type (WT) kinases. Importantly, the engineered kinase is a non-orthogonal mutant protein, i.e. it can still phosphorylate endogenous substrates. A wide range of kinase-inhibitor pairs were generated, displaying incomparable potency and specificity compared to known inhibitors [5].

Inspired by this approach, neuroscientists developed orthogonal receptor-ligand pairs, the most widely used being the Designer Receptors Exclusively Activated by Designer Drugs (DREADDs) [6,7]. DREADDs are modified G-protein coupled receptors (GPCRs) engineered through directed molecular evolution, that are insensitive to their natural ligands but sensitive 
to synthetic agonists (Figure 2A). The original DREADDs (hM3Dq and hM4Di) are based on human M3 and M4 muscarinic receptors, which couple to $\mathrm{Gq}$ and $\mathrm{Gi}$, respectively [6]. hM3Dq and hM4Di are made insensitive to acetylcholine (ACh), sensitive to the synthetic ligand clozapine-N-oxyde (CNO), and importantly show minimal basal activity in the absence of chemical activation (but see [8]). hM3Dq is classically used for enhancing neuronal activity, while hM4Di is used for neuronal inhibition. Newer DREADDs include GsD that couples to Gs, $\mathrm{hM} 4 \mathrm{D}^{\mathrm{nrxn}}$ that is axonally targeted and affords pre-synaptic inhibition, and a $\kappa$-opioid-derived DREADD (KORD) that operates with salvinorin B [9], a compound distinct from CNO, thus allowing multiplexed and bidirectional modulation of neuronal activity and behavior.

Receptor-ligand pairs have also been developed for ligand gated ion channels (LGICs, Figure $2 B$ ). The ligand binding domain (LBD) of the $\alpha 7$ nicotinic acetylcholine receptor (nAChR), referred to as pharmacologically selective actuator module (PSAM), was engineered to respond solely to synthetic molecules called pharmacological selective effector molecules (PSEM) $[10,11]$. Activation of PSAM by PSEMs induces either cation, calcium or chloride influx, depending on the ion pore domain (IPD) spliced onto the LBD (serotonin 5HT3, $\alpha 7-n A C h R$ or glycine receptor IPD, respectively). Hence PSAMs can be used to either drive or suppress neuronal activity, or to increase intracellular calcium, in genetically-targeted neurons. DREADDS, and to a lesser extent PSAMs, have proven extremely valuable tools for the manipulation of circuits with cellular specificity, providing crucial information as to how circuits shape behavior $[7,12]$. However, because they are no longer sensitive to their cognate ligands, DREADDs and PSAMs are constraint to decode the nervous system at the circuit level, and cannot be used for the molecular dissection of the role of endogenous GPCR or LGIC signaling in the modulation of circuits and behaviors.

With the advent of optogenetics [13], light-based strategies for controlling brain proteins have emerged, affording improved spatio-temporal resolution over chemical approaches [1]. Notably, light-controllable adrenergic, opioid, serotoninergic and glutamatergic GPCRs (OptoXRs) have been engineered $[14,15]$. Opto-XRs are chimeric proteins, usually engineered with a mammalian opsin (e.g. rhodopsin or melanopsin) and the intracellular loops and C-terminal tail of endogenous GPCRs (Figure 2C). In addition to trafficking and signaling like their native counterparts, OptoXRs are photo-activatable, offering the possibility to mimic the spatio- 
temporal dynamics of neuromodulator signaling in vivo. Nevertheless, Opto-XRs bind retinal and therefore lack responsiveness to endogenous ligands, restricting their use, as with DREADDS, to a circuit-level understanding of brain function.

Dissecting the role of endogenous receptors and channels in behaviors requires maintaining their natural pharmacology and signaling properties. To this aim, two receptor-ligand pair-like approaches have been developed for $G A B A_{A}$ receptors $\left(G A B A_{A} R s\right)$ and $n A C h R s$. $G A B A_{A} R$ signaling is potentiated by the allosteric modulator zolpidem, yet only when the $\gamma 2$ subunit is present in the receptor. A single mutation (phenylalanine to isoleucine) at position 77 on the $\gamma 2$ subunit is sufficient to convert a zolpidem-sensitive into a zolpidem-insensitive receptor (Figure 2D) [16]. In transgenic mice expressing $\gamma 2$ (lle77), sensitivity to zolpidem can be restored in a tissue-specific fashion using Cre-recombinases that switch $\gamma 2$ (Ile77) to $\gamma 2$ (Phe77). Zolpidem-sensitivity was notably restricted to cerebellar Purkinje neurons, to show that potentiation of GABAergic inhibition in these cells induces motor deficits [17]. Even though motor deficits had been observed after zolpidem administration in WT mice, interpretation was ambiguous considering the profound sedative effects of this compound. Furthermore, mice with a deletion of $\gamma 2$ in Purkinje cells show no motor deficit, emphasizing the importance of developing cell-specific pharmacology approaches for acute interventions. Nevertheless, it should be noted that this strategy requires triple crosses of mouse lines, making it technologically demanding.

In nAChRs, the strategy was referred to as gain-of-function mutations [18]. The idea is to increase agonist sensitivity in a subtype-specific fashion using site-directed mutagenesis, and to use sub-threshold doses of nicotine for isoform-selective activation (Figure 2E). The leucine residue in position $9^{\prime}$ on the transmembrane (TM) segment $\mathrm{M} 2$ is a conserved residue that, when mutated to alanine, serine or threonine in the $\alpha$ subunit, considerably reduces the energy required to open the channel, resulting in a "hypersensitive" mutant with increased agonist sensitivity [18]. Using the Cre-lox technology, expression of such hypersensitive mutants could be restricted to specific neurons such as GABAergic cells of the ventral tegmental area or cholinergic neurons of the medial habenula, unveiling new roles for $\alpha 4$ nAChRs in reward and anxiety, respectively $[19,20]$. However, it should be noted that these 
mutant receptors are also more sensitive to endogenous acetylcholine (ACh), which may result in unintended neuronal adaptations.

\section{The tethered-ligand approach}

The overall strategy is to increase local concentration of the drug at the cell surface through covalent attachment [21]. One major advantage of this approach is that once bio-conjugation is achieved, there is no need for reapplication of the drug.

\section{Membrane-tethered ligands}

A first example is based on genetically-encoded ligands that are self-embedded in cell membranes. The fusion construct is composed of a peptide linked by a flexible linker to the extracellular side of the membrane, either through a TM segment or a glycosyl-phosphatidylinositol (GPI) anchor (Figure 3A) [22-27]. The peptide ligand can either be an agonist (tpeptide) or an antagonist (t-toxin). This versatile approach has been successfully applied to activate class B GPCRs [22] and to inhibit specific voltage-gated sodium $\left(\mathrm{Na}_{v}\right)$ and calcium $\left(\mathrm{Ca}_{\mathrm{v}}\right)$ channels as well as nAChRs [24-27]. Toxins can be extremely specific for a particular type of ion channel, enabling blockade of $\mathrm{NA}_{v} 1.7$ without affecting $\mathrm{Na}_{v} 1.8$ for instance [28]. However, since the ligand is permanently expressed at the membrane, the action of t-peptides and ttoxins is irreversible. T-toxin expression can be placed under the control of a Tet-on/Tet-off system, allowing antagonism to be triggered on and off, yet still with very slow kinetics (days) [24]. Consequently, these tools have been used for chronic inhibition of neuronal activity and genetic dissection of neurophysiological circuits rather than for acute, cell-specific pharmacology. T-toxins were notably used in freely-moving mice, where chronic inhibition of $\mathrm{Ca}_{\mathrm{v}} 2.1$ and $\mathrm{Ca}_{\mathrm{v}} 2.2$ allowed probing the role of thalamo-striatal excitatory synaptic transmission in the susceptibility to social stress [27].

An extension of this approach is to include in the construct a photosensitive group to afford reversibility. Notably, the light-oxygen voltage (LOV) protein domain from plants was used to produce Lumitoxins, light-controllable membrane-tethered toxins (Figure 2B) [29]. LOV domains incorporate a flavin chromophore, ubiquitously present in mammalian cells, and 
changes conformation upon illumination with blue light. In darkness, Lumitoxins produce sustained block of voltage-gated potassium (Kv) channels, while illumination results in rapid (seconds) channel unblock. The LOV domain returns to its resting state slowly in darkness, restoring blockade within minutes. Specific Kv homologues such as Kv1.1, Kv1.2 or Shaker can be photosensitized using appropriate membrane-tethered toxins. However, this technique has not yet been extended to other protein families and has not been deployed in vivo.

Another strategy, called Drug Acutely Restricted by Tethering (DART), relies on a bacterial enzyme called HaloTag for capturing drugs at the cell surface [3]. HaloTag is a self-labeling enzyme that catalyzes the covalent attachment of synthetic molecules containing a HaloTag Ligand (HTL) with very high efficiency and specificity (Box 1). In DART, the HaloTag is expressed at the cell surface through a TM domain. The synthetic ligand is composed of an active drug linked to the HTL through a Poly-Ethylene Glycol (PEG) flexible linker. Once infused, it attaches to the HaloTag, resulting in a hundred-fold elevation of drug concentration at the cell surface. This strategy is unique in that it offers acute pharmacological manipulation (seconds to minutes) of native receptors with cellular specificity. However, the effect is only very slowly reversible (days). DART has been applied to AMPA receptors (AMPARs) and metabotropic muscarinic receptors (mAChRs), showing that the method can be applied to different receptor types. Specific inhibition of AMPARs in distinct neuronal populations of the dorsal striatum (D1 versus D2 neurons) revealed that activity of these receptors is causally linked with the akinesia observed in a mouse model of Parkinson's disease. Moreover, antagonism of AMPARs expressed on D2-, but not D1-, neurons had therapeutic effects on motor dysfunction, illustrating the power of targeting drugs to specific cell types.

\section{Receptor-tethered ligands}

Various strategies have been developed to tether ligands directly to their receptors. In the RECON (REductively Cleavable agONist) approach, a GPCR is N-terminally fused to a SNAPtag [30], another type of self-labeling tag. The tethered ligand combines a peptide agonist for either class A or B GPCR, a central PEG linker bearing a disulfide bridge, and a SNAP-tag substrate. This synthetic ligand covalently and specifically attaches to the SNAP-tag, resulting in permanent receptor activation. The disulfide bridge can be cleaved with redox agents, 
resulting in slow agonist dissociation. This method should be especially useful for studying GPCR activation and internalization in vitro; however, its use for neuropharmacology is elusive.

Increasing local agonist concentration at the receptor surface does not necessarily require covalent attachment. Another design is to install a His-tag on a GPCR, and to use a Metalcomplex Agonist Conjugate (MAC) that binds with high affinity to the His-tag through coordination tethering (Figure 3D) [31]. Affinity of the synthetic ligand is 10-100 higher for the engineered than for the WT receptor. Interaction between MAC and the His-tag is not covalent, hence activation is reversible. The MAC strategy was used for cell-specific control of class A GPCRs ( $\beta 2$ adrenoreceptors and mAChRs), but its efficacy in vivo has not been reported yet.

One major drawback of tethered ligands is irreversibility of action. One solution to this issue is to incorporate a chemical photoswitch in the ligand, and use light to trigger binding/unbinding. This can be achieved by anchoring a photoswitchable tethered ligand (PTL) onto a cysteine-substituted receptor (Figure 3E). The cysteine mutation is incorporated in proximity to a ligand-binding site. The PTL is made of three elements: a maleimide moiety, which is a thiol-reactive group for attachment to cysteines; a central azobenzene photoswitch; and a bioactive ligand (agonist, antagonist or pore-blocker). Light is used to reversibly change the geometry of the photoswitch from elongated to twisted, which triggers binding/unbinding. This opto-chemogenetic strategy allows reversible control of receptors with very high spatial and temporal precision. The PTL approach has proven to be highly versatile. It has been applied to potassium channels [32-34], ionotropic [35-37] and metabotropic [38] glutamate receptors, $n A C h R s ~[4,39], \mathrm{GABA}_{A} \mathrm{Rs}[40,41]$, dopamine receptors [42] as well as P2X receptors [43]. It was used to probe neurotransmission in various neuronal settings, both ex and in vivo in zebrafish and mice [1]. In zebrafish, the photoswitch can simply be added to the swimming water, but in mice it has to be locally delivered. Despite this drawback, the PTL approach has been applied in the living mouse, notably for restoring vision to blind mice [44], for manipulating action potential firing [45] and GABAergic inhibition [41] in the visual cortex, or for controlling nicotinic transmission in the ventral tegmental area and addiction-related behaviors [4]. One potential shortcoming of PTLs is their non-selective 
attachment to endogenous cysteines, even though no adverse effect has been observed so $\operatorname{far}[4,41]$.

More specific bioconjugation (Box 1) can be achieved with the Photoswitchable Orthogonal Remotely Tethered Ligand (PORTL) approach, which uses self-labelling enzymes such as SNAPor CLIP-tags (Figure 3F) [46-48]. These self-labeling tags can be fused directly to receptors $[46,47]$ or alternatively to nanobodies [48], an interesting alternative for proteins for which incorporation of the tag is prohibited. Light is used to change the geometry of the ligand, and thereby its affinity for the protein. This technology has so far only been applied to metabotropic glutamate receptors, and was used to restore patterned vision in a blind mouse 271 model [49].

Another alternative for site-specific bioconjugation is the Bio-Orthogonal Ligand Tethering (BOLT) technique, which is based on the incorporation of unnatural amino acids (UAA) in proteins [50]. The UAA is used as a biorthogonal handle for attachment of a synthetic ligand through click-chemistry. BOLT demonstrated selective inhibition of kinases in mammalian cells, and can be made photo-reversible by introducing a photoisomerizable group to the ligand (photoBOLT). Expansion of the genetic code in the mouse is technically challenging[51], but the recent generation of transgenic animals carrying a tRNA synthetase / tRNA pair into their genome should facilitate future use [52].

\section{Intracellular delivery approaches}

Intracellular, cell-specific delivery can also be achieved, allowing targeting not only cellsurface receptors but also enzymes and signaling pathways (Figure 1E). Two different approaches have been described.

\section{The enzyme-prodrug pair approach}

This approach relies on selective enzyme-substrate pairs to convert an inert prodrug into an active molecule (Figure 1E) [53]. The drug is masked by a disposable blocking group that is hydrolyzed specifically by an exogenous enzyme, but not by native ones. Expression of the 
specific enzyme in genetically-targeted cells allows unmasking the drug in a cell-specific fashion. The challenges were to develop an ester masking group with high stability towards hydrolysis by endogenous esterases, and to find an esterase that would hydrolyze this ester bond with high efficiency. Screening resulted in the discovery of porcine liver esterase (PLE), an enzyme that efficiently hydrolyzes the cyclopropylmethyl carboxyl (CM) ester masking group [53]. More recently, another selective enzyme-substrate pair was developed, based on engineered variants of E. coli nitroreductase (NTR) and a nitroimidazol (NM) masking group [54]. This strategy has proven highly generalizable to various masked small molecules such as fluorophores, calcium indicators, enzyme inhibitors, CAMP analogs or ion channel blockers [53-55]. Notably, the masked compound CM-MK801 was used to confirm, in brain slices, the role of dopamine neuron-expressed NMDA receptors in cocaine-induced plasticity [55]. Both the $\mathrm{CM}$ and $\mathrm{NM}$ groups were shown to be highly stable in neurons, an important requirement for cell-specificity. That said, care must be taken because drugs that are too membrane permeable may diffuse out of the target neuron and affect nearby cells non-selectively. This limitation can be circumvented, for instance by increasing polarity of the compound [54]. The biggest challenge for future applications remains to use this technology in vivo. So far, the limited aqueous solubility of the masked compounds precludes direct brain delivery. In addition, systemic application of CM-masked drugs is prohibited as well because CM is not resistant to esterases expressed in the periphery.

\section{Facilitated diffusion through large ion-channel pores}

Another approach is based on the selective intracellular diffusion of membrane-impermeant drugs through large ion channels (Figure 1E). The capsaicin TRPV1 and some P2X receptors open a very large pore when activated, allowing permeation of large organic cations $[56,57]$. This biophysical property was ingeniously exploited to facilitate the entry of QX-314, a membrane-impermeant lidocaine derivative, into pain-sensing neurons [58]. QX-314 is normally inert on neurons because it has an intracellular site of action in $\mathrm{Na}_{v} s$. However, it can selectively enter nociceptors by diffusing through open TRPV1 channels, which are abundant

322 in these cells but virtually absent in other neurons. QX-314 remains trapped inside pain neurons for hours, resulting in long-lasting local analgesia [58-60]. To gain rapidly reversible control over nociception, we designed a photoswitchable version of QX-314, named QAQ [61- 
63]. QAQ can rapidly and reversibly block blocks $\mathrm{Na}_{\mathrm{v}} \mathrm{s}$ in nociceptors, switching pain signaling on and off upon illumination with the appropriate wavelength of light.

Unlike all the methods presented in this review, this strategy does not necessarily require genetic manipulation. Rather, it exploits the sparse distribution of TRPV1 channels or P2X receptors to achieve targeted cell loading, and thus bears potential therapeutic interest. So far, QX-314 and QAQ were co-administered with capsaicin to enable selective cell entry. Yet, recent studies suggest that capsaicin may not always be needed, since TRPV1 channels in central terminals are extensively hyperactive in neuropathic pain models [64]. Similarly, the retina was shown to be highly remodeled in animal models of retinal degeneration [65], with $\mathrm{P} 2 \mathrm{X}$ receptors functionally upregulated in retinal ganglion cells [66]. This feature was exploited to deliver photoswitchable blockers of potassium channels $[61,67]$ specifically to OFF-ganglion cells, thereby restoring visual responses to blind retinas $[65,66]$.

\section{Concluding remarks}

Investigating the role of individual receptors and ion channels in particular brain regions requires methods for perturbing protein activity selectively, acutely, reversibly and in a cellspecific fashion, ideally in the behaving animal. Diverse methods are being developed toward this goal. Yet no method is universal, and virtually all have shortcomings, especially when considering their use in vivo. One important limitation lies in the limited therapeutic window for selective agonism / antagonism, which is classically in the range 10-100 fold (Table 1). Recent studies demonstrate that with some optimization, very potent agonists with exceptional selectivity (>10 000 fold) can be generated for PSAMs [11] and DREADDs [68], suggesting that such selectivity should be in principle attainable for other designer receptors. Full orthogonality can even be achieved, for instance using light-based methods (after ligand bioconjugation for PTLs and PORTLs). Yet, there is still a need for orthogonal labeling motifs that are efficient at lower doses (Box 1).

There is also a need for caution and appropriate controls when using chemogenetic 355 approaches, even when reported to be fairly orthogonal. For instance, CNO was originally selected because of its excellent drug-like properties, but recent reports show that in vivo it is 
metabolically back-converted to clozapine, a molecule that not only activates DREADDs but also many other endogenous GPCRs [69]. Importantly, non-CNO analogues with improved selectivity have been developed, notably compound 21 [70] and perlapine [68], circumventing this potential issue.

Another important limitation to consider is invasiveness. DREADD activators, PSEMs, nicotine and zolpidem have rapid central nervous system (CNS) penetration and distribution in mice and can therefore be applied systemically $[7,17,18,71]$. But other approaches require local drug delivery in brain tissue through a cannula guide, either because of the instability of the compound in aqueous medium (e.g. maleimide-based PTLs) or because of poor blood brain penetration (e.g. DART), or both. Methods for improved systemic delivery are awaited. Similarly, the optical tools described in this review classically work with visible light (Table 1) and therefore require local light delivery with a chronically implanted optic fiber. Red-shifted chromophores that operate at more deeply-penetrating wavelengths such as near-infra-red light are currently under development [72] and should facilitate remote, transcranial control in the future.

Another important aspect to consider is receptor-type specificity. Techniques like DART or intracellular delivery methods target native receptors and therefore cannot differentiate between different receptor isoforms expressed on the same cell. Toxin-based methods provide increased selectivity but whether they can be used for acute and reversible control of receptors and ion channels in vivo is unclear. On the other hand, methods that require genetic engineering of receptors, like PTL or PORTL, provide absolute receptor-type specificity and can help dissect the role of individual receptor subtypes in a circuit. However, molecular specificity comes at a cost: the requirement for ectopic expression of the target protein, which may affect expression level and/or patterns. Methods for overcoming this issue include the generation of transgenic knock-in animals [41]- ideally in a tissue-specific fashion- or the use of a subunit replacement strategy [34].

Finally, these tools bear strong potential not only for research purposes in animal models, but also for therapeutic applications in humans. Indeed, targeting drugs to particular neuronal populations may improve therapeutic efficacy, while decreasing the side effects associated 
with insufficient selectivity of conventional approaches. For instance, QX-314 or QAQ can selectively block the function of pain-sensing neurons in rodents, while leaving other sensory modalities unaffected $[58,59,62]$, and do not require genetic modification, making them

392 potential drug-like candidates for pain-selective local anesthesia in humans. Approaches 393 requiring genetic manipulation are also being explored to treat CNS diseases in a titrated and 394 cell-specific manner. This includes strategies for restoring the balance of excitation/inhibition 395 selectively in epileptogenic zones, or for treating movement disorder in Parkinson's disease. 396 The DART technology for instance revealed that antagonizing AMPARs expressed on D2 397 neurons of the basal ganglia was much more efficient at improving motor dysfunction than 398 global antagonism through D1 and D2 neurons. Yet it is not clear how this finding can be 399 translated into human therapy. DREADDs and PSAMs are currently progressing into non400 human primates [73,74], an important step towards being used as treatment to people. In 401 addition, hM4Di, KORD and new-generation PSAMs can be potently activated by low doses of 402 olanzapine [75], salvinorin B [9] and varenecline [71], respectively, three drugs that are 403 already clinically approved, thus facilitating translation to humans. Despite these important 404 advances, considerable obstacles for implementing such approaches to the clinic remain, 405 notably those associated with gene therapy and, to a lesser extent, drug delivery and 406 selectivity. 
Table 1: Cell-specific neuropharmacology approaches.

409 N.R.: not reported; N.A.: not applicable

\begin{tabular}{|c|c|c|c|c|c|c|c|c|}
\hline Tool Name & Receptor & Ligand & $\begin{array}{l}\text { On } \\
\text { timescale }\end{array}$ & $\begin{array}{l}\text { Off } \\
\text { timescal } \\
\text { e }\end{array}$ & $\begin{array}{l}\text { Therapeutic } \\
\text { window } \\
\text { (fold) }\end{array}$ & Application & $\begin{array}{l}\text { In vivo } \\
\text { application }\end{array}$ & Refs \\
\hline \multicolumn{9}{|c|}{ Receptor-ligand pairs } \\
\hline DREADDS & $\begin{array}{l}\text { Synthetic } \\
\text { GPCR }\end{array}$ & $\begin{array}{l}\text { Synthetic } \\
\text { (CNO, } \\
\text { perlapine...) }\end{array}$ & $\mathrm{s}-\mathrm{min}$ & $\begin{array}{l}\text { min- } \\
\text { hour }\end{array}$ & $100-10000$ & $\begin{array}{l}\text { On/off control } \\
\text { of neuronal } \\
\text { activity }\end{array}$ & $\begin{array}{l}\text { Drosophila, } \\
\text { mice, rats, } \\
\text { monkeys }\end{array}$ & {$[6,7]$} \\
\hline PSAM/PSEM & Synthetic LGIC & $\begin{array}{l}\text { Synthetic } \\
(22 \mathrm{~S}, 89 \mathrm{~S} \ldots)\end{array}$ & $\mathrm{s}-\mathrm{min}$ & $\begin{array}{l}\text { min- } \\
\text { hour }\end{array}$ & $30->10000$ & $\begin{array}{l}\text { On/off control } \\
\text { of neuronal } \\
\text { activity }\end{array}$ & Mice & $\begin{array}{l}{[10,11} \\
]\end{array}$ \\
\hline Opto-XR & $\begin{array}{l}\text { Opsin-GPCR } \\
\text { chimera }\end{array}$ & $\begin{array}{l}\text { Retinal + Blue } \\
\text { light }\end{array}$ & $\mathrm{ms}-\mathrm{s}$ & ms-s & $\begin{array}{l}\text { Fully } \\
\text { orthogonal } \\
\text { (light) }\end{array}$ & $\begin{array}{l}\text { Activation of G } \\
\text { protein } \\
\text { signaling }\end{array}$ & Mice & $\begin{array}{l}{[14,15} \\
]\end{array}$ \\
\hline $\begin{array}{l}\text { Zolpidem- } \\
\text { insensitive } \\
G_{B A A_{A} R}\end{array}$ & $\begin{array}{l}\text { Mutant } \\
\text { GABA }_{A} R\end{array}$ & $\begin{array}{l}\text { Synthetic } \\
\text { (Zolpidem) }\end{array}$ & $\mathrm{s}-\mathrm{min}$ & $\begin{array}{l}\text { min- } \\
\text { hour }\end{array}$ & $>600$ & $\begin{array}{l}\text { Modulation of } \\
\text { GABA }_{A} R s\end{array}$ & Mice & [17] \\
\hline $\begin{array}{l}\text { Gain of } \\
\text { function } \\
\text { nAChRs }\end{array}$ & $\begin{array}{l}\text { Mutant } \\
\text { nAChR }\end{array}$ & $\begin{array}{l}\text { Exogenous } \\
\text { (Nicotine) and } \\
\text { endogenous } \\
\text { (ACh) }\end{array}$ & $\mathrm{s}-\mathrm{min}$ & $\begin{array}{l}\text { min- } \\
\text { hour }\end{array}$ & $10-100$ & $\begin{array}{l}\text { Activation of } \\
\text { nAChR subtypes }\end{array}$ & Mice & $\begin{array}{l}{[19,20} \\
]\end{array}$ \\
\hline \multicolumn{9}{|c|}{ Membrane-tethered ligands } \\
\hline $\begin{array}{l}\text { t-toxins and t- } \\
\text { peptides }\end{array}$ & $\begin{array}{l}\text { Native } \\
\text { receptors and } \\
\text { ion channels }\end{array}$ & $\begin{array}{l}\text { Genetically- } \\
\text { encoded } \\
\text { toxins or } \\
\text { peptides }\end{array}$ & $\begin{array}{l}\text { Always on } \\
\text { (days with } \\
\text { Tet-on } \\
\text { system) }\end{array}$ & $\begin{array}{l}\text { Irreversi } \\
\text { ble } \\
\text { (days } \\
\text { with } \\
\text { Tet-off } \\
\text { system) } \\
\end{array}$ & $\begin{array}{l}\text { N.A. } \\
\text { (constitutiv } \\
\text { e) }\end{array}$ & $\begin{array}{l}\text { Genetic } \\
\text { dissection of } \\
\text { circuits }\end{array}$ & $\begin{array}{l}\text { Drosophila, } \\
\text { zebrafish, } \\
\text { mice }\end{array}$ & $\begin{array}{l}22- \\
27]\end{array}$ \\
\hline Lumitoxin & $\begin{array}{l}\text { Native } \\
\text { receptors and } \\
\text { ion channels }\end{array}$ & $\begin{array}{l}\text { Genetically- } \\
\text { encoded } \\
\text { toxins + blue } \\
\text { light }\end{array}$ & $\min$ & $\mathrm{s}$ & $\begin{array}{l}\text { Fully } \\
\text { orthogonal } \\
\text { (light) }\end{array}$ & $\begin{array}{l}\text { Block of ion } \\
\text { channel } \\
\text { subtypes }\end{array}$ & N.R. & [29] \\
\hline DART & $\begin{array}{l}\text { Native AMPA } \\
\text { receptors }\end{array}$ & $\begin{array}{l}\text { HaloTag- } \\
\text { reactive } \\
\text { ligand }\end{array}$ & $\mathrm{s}-\mathrm{min}$ & days & $30-300$ & $\begin{array}{l}\text { Antagonism of } \\
\text { AMPARs and } \\
\text { mAChRs }\end{array}$ & Mice & [3] \\
\hline \multicolumn{9}{|c|}{ Receptor-tethered ligands } \\
\hline RECON & $\begin{array}{l}\text { SNAP-tagged } \\
\text { GPCR }\end{array}$ & $\begin{array}{l}\text { SNAP-reactive } \\
\text { ligand }\end{array}$ & $\mathrm{s}-\mathrm{min}$ & $\begin{array}{l}\text { Irreversi } \\
\text { ble (min } \\
\text { with } \\
\text { redox } \\
\text { agent) }\end{array}$ & N.A. & $\begin{array}{l}\text { Activation and } \\
\text { internalization } \\
\text { of GPCRs }\end{array}$ & N.R. & {$[30]$} \\
\hline MAC & $\begin{array}{l}\text { His-tagged } \\
\text { GPCR }\end{array}$ & $\begin{array}{l}\text { Metal } \\
\text { complex- } \\
\text { agonist } \\
\text { conjugate }\end{array}$ & $\mathrm{s}-\mathrm{min}$ & $\min$ & $10-100$ & $\begin{array}{l}\text { Activation of } \\
\text { GPCRs }\end{array}$ & N.R. & [31] \\
\hline PTL & $\begin{array}{l}\text { Cysteine- } \\
\text { substituted } \\
\text { receptor }\end{array}$ & $\begin{array}{l}\text { Thiol-reactive } \\
\text { ligand + UV- } \\
\text { visible light }\end{array}$ & $\mathrm{ms}-\mathrm{s}$ & $\mathrm{ms}-\mathrm{s}$ & $\begin{array}{l}\text { N.A. } \\
\text { (orthogonal } \\
\text { after } \\
\text { attachment) }\end{array}$ & $\begin{array}{l}\text { On/off control } \\
\text { of receptors } \\
\text { and ion } \\
\text { channels }\end{array}$ & $\begin{array}{l}\text { Zebrafish, } \\
\text { mice }\end{array}$ & $\begin{array}{l}{[4,32-} \\
43]\end{array}$ \\
\hline PORTL & $\begin{array}{l}\text { SNAP- or CLIP- } \\
\text { tagged GPCR } \\
\text { or nanobody }\end{array}$ & $\begin{array}{l}\text { SNAP- or CLIP- } \\
\text { reactive } \\
\text { ligand + UV- } \\
\text { visible light }\end{array}$ & $\mathrm{ms}-\mathrm{s}$ & $\mathrm{ms}-\mathrm{s}$ & $\begin{array}{l}\text { N.A. } \\
\text { (orthogonal } \\
\text { after } \\
\text { attachment) }\end{array}$ & $\begin{array}{l}\text { On/off control } \\
\text { of receptors }\end{array}$ & Mice & $\begin{array}{l}{[46-} \\
48]\end{array}$ \\
\hline $\begin{array}{l}\text { iBOLT (and } \\
\text { photoBOLT) }\end{array}$ & $\begin{array}{l}\text { Receptor } \\
\text { mutated with } \\
\text { unnatural } \\
\text { aminoacid }\end{array}$ & $\begin{array}{l}\text { Click } \\
\text { chemistry- } \\
\text { reactive } \\
\text { ligand (+ UV } \\
\text { light) }\end{array}$ & $\min -\mathrm{h}$ & $\begin{array}{l}\text { Irreversi } \\
\text { ble (min } \\
\text { with } \\
\text { light) }\end{array}$ & N.A. & $\begin{array}{l}\text { Inhibition of } \\
\text { protein activity } \\
\text { (reversible with } \\
\text { light) }\end{array}$ & N.R. & {$[50]$} \\
\hline
\end{tabular}




\begin{tabular}{|c|c|c|c|c|c|c|c|c|}
\hline $\begin{array}{l}\text { Enzyme-pro } \\
\text { drug pair }\end{array}$ & $\begin{array}{l}\text { Native } \\
\text { proteins }\end{array}$ & Masked drug & $\min$ & $\begin{array}{l}\text { Irreversi } \\
\text { ble }\end{array}$ & N.A. & $\begin{array}{l}\text { Control of } \\
\text { protein activity }\end{array}$ & N.R. & $\begin{array}{l}{[53-} \\
55]\end{array}$ \\
\hline $\begin{array}{l}\text { Facilitated } \\
\text { diffusion } \\
\text { through large } \\
\text { ion channels }\end{array}$ & $\begin{array}{l}\text { Native } \\
\text { proteins }\end{array}$ & $\begin{array}{l}\text { Membrane- } \\
\text { impermeant } \\
\text { and cationic } \\
\text { (+UV-visible } \\
\text { light) }\end{array}$ & $\begin{array}{l}\text { Min (ms-s } \\
\text { with light) }\end{array}$ & $\begin{array}{l}\text { Days } \\
\text { (ms-s } \\
\text { with } \\
\text { light) }\end{array}$ & N.A. & $\begin{array}{l}\text { Block of ion } \\
\text { channels } \\
\text { (on/off with } \\
\text { light) }\end{array}$ & Mice, rats & $\begin{array}{l}{[58-} \\
60,62, \\
63,65, \\
66]\end{array}$ \\
\hline
\end{tabular}

410

411 Acknowledgement: We wish to thank Fabio Marti and Philippe Faure (Sorbonne Université)

412 for their comments on the manuscript. This work was supported by grants from the Fondation 413 pour la Recherche Médicale FRM (Equipe FRM DEQ2013326488), the Brain and Behavior 414 Research Foundation (NARSAD Young Investigator Grant), the Agence Nationale de la 415 Recherche (ANR-JCJC), the Institut National Du Cancer (TABAC-16-022) and the Fondation de 416 France (Fondation Médisite). SM and RDC were recipient of a 4th year PhD fellowship from 417 FRM (FDT201904008060 and FDT20170437427, respectively). 
Paoletti, P. et al. (2019) Optical control of neuronal ion channels and receptors. Nat Rev Neurosci under review,

Hüll, K. et al. (2018) In Vivo Photopharmacology. Chem. Rev. DOI: 10.1021/acs.chemrev.8b00037

Shields, B.C. et al. (2017) Deconstructing behavioral neuropharmacology with cellular specificity. Science 356, Durand-de Cuttoli, R. et al. (2018) Manipulating midbrain dopamine neurons and reward-related behaviors with light-controllable nicotinic acetylcholine receptors. eLife 7, 15991

Bishop, A.C. et al. (2000) A chemical switch for inhibitor-sensitive alleles of any protein kinase. Nature 407, 395-401

Armbruster, B.N. et al. (2007) Evolving the lock to fit the key to create a family of $\mathrm{G}$ protein-coupled receptors potently activated by an inert ligand. Proceedings of the National Academy of Sciences 104, 5163-5168 Roth, B.L. (2016) DREADDs for Neuroscientists. Neuron 89, 683-694 Saloman, J.L. et al. (2016) Gi-DREADD Expression in Peripheral Nerves Produces Ligand-Dependent Analgesia, as well as Ligand-Independent Functional Changes in Sensory Neurons. J. Neurosci. 36, 10769-10781 Vardy, E. et al. (2015) A New DREADD Facilitates the Multiplexed Chemogenetic Interrogation of Behavior. Neuron 86, 936-946 Magnus, C.J. et al. (2011) Chemical and Genetic Engineering of Selective Ion Channel-Ligand Interactions. Science 333, 1292-1296 Magnus, C.J. et al. (2019) Ultrapotent chemogenetics for research and potential clinical applications. Science DOI: 10.1126/science.aav5282 Atasoy, D. and Sternson, S.M. (2018) Chemogenetic Tools for Causal Cellular and Neuronal Biology. Physiological Reviews 98, 391-418 Kim, C.K. et al. (2017) Integration of optogenetics with complementary methodologies in systems neuroscience. Nat Rev Neurosci 18, 222-235 Airan, R.D. et al. (2009) Temporally precise in vivo control of intracellular signalling. Nature DOI: 10.1038/nature07926 
Spangler, S.M. and Bruchas, M.R. (2017) Optogenetic approaches for dissecting neuromodulation and GPCR signaling in neural circuits. Current Opinion in Pharmacology 32, 56-70

Buhr, A. et al. (1997) Subtle changes in residue 77 of the gamma subunit of alpha1beta2gamma2 GABAA receptors drastically alter the affinity for ligands of the benzodiazepine binding site. Journal of Biological Chemistry 272, 1179911804

Wulff, P. et al. (2007) From synapse to behavior: rapid modulation of defined neuronal types with engineered GABAA receptors. Nature Neuroscience 10, 923929

Drenan, R.M. and Lester, H.A. (2012) Insights into the Neurobiology of the Nicotinic Cholinergic System and Nicotine Addiction from Mice Expressing Nicotinic Receptors Harboring Gain-of-Function Mutations. Pharmacological Reviews 64, 869-879 Ngolab, J. et al. (2015) Functional Upregulation of $\alpha 4 *$ Nicotinic Acetylcholine Receptors in VTA GABAergic Neurons Increases Sensitivity to Nicotine Reward. J. Neurosci. 35, 8570-8578 Pang, X. et al. (2016) Habenula cholinergic neurons regulate anxiety during nicotine withdrawal via nicotinic acetylcholine receptors. Neuropharmacology $107,294-304$

Leippe, P. et al. (2017) Specificity and Speed: Tethered Photopharmacology. Biochemistry 56, 5214-5220 Fortin, J.-P. et al. (2009) Membrane-tethered ligands are effective probes for exploring class B1 G protein-coupled receptor function. Proceedings of the National Academy of Sciences 106, 8049-8054 Choi, C. and Nitabach, M.N. (2013) Membrane-Tethered Ligands: Tools for CellAutonomous Pharmacological Manipulation of Biological Circuits. Physiology 28, 164-171

Auer, S. et al. (2010) Silencing neurotransmission with membrane-tethered toxins. Nature Methods DOI: 10.1038/nmeth.1425 Ibañez-Tallon, I. and Nitabach, M.N. (2011) Tethering toxins and peptide ligands for modulation of neuronal function. Current Opinion in Neurobiology DOI: 
10.1016/j.conb.2011.11.003

Ibañez-Tallon, I. et al. (2004) Tethering Naturally Occurring Peptide Toxins for Cell-Autonomous Modulation of Ion Channels and Receptors In Vivo. Neuron 43, $7-7$

Christoffel, D.J. et al. (2015) Excitatory transmission at thalamo-striatal synapses mediates susceptibility to social stress. Nature Neuroscience $18,962-964$ Stürzebecher, A.S. et al. (2010) An in vivo tethered toxin approach for the cellautonomous inactivation of voltage-gated sodium channel currents in nociceptors. The Journal of Physiology 588, 1695-1707

Schmidt, D. et al. (2014) A fully genetically encoded protein architecture for optical control of peptide ligand concentration. Nature Communications 5, 1-8

Podewin, T. et al. (2018) Conditional and Reversible Activation of Class A and B G Protein-Coupled Receptors Using Tethered Pharmacology. ACS Cent. Sci. 4, 166179

Kubota, R. et al. (2018) Chemogenetic Approach Using Ni(II) Complex-Agonist Conjugates Allows Selective Activation of Class A G-Protein-Coupled Receptors. ACS Cent. Sci. 4, 1211-1221

Banghart, M.R. et al. (2004) Light-activated ion channels for remote control of neuronal firing. Nature Neuroscience 7, 1381-1386

Fortin, D.L. et al. (2011) Optogenetic photochemical control of designer K+ channels in mammalian neurons. Journal of Neurophysiology 106, 488-496 Sandoz, G. et al. (2012) Optical Control of Endogenous Proteins with a Photoswitchable Conditional Subunit Reveals a Role for TREK1 in GABAB Signaling. Neuron 74, 1005-1014

Volgraf, M. et al. (2005) Allosteric control of an ionotropic glutamate receptor with an optical switch. Nature Chemical Biology 2, 47-52

Szobota, S. et al. (2007) Remote Control of Neuronal Activity with a Light-Gated Glutamate Receptor. Neuron 54, 535-545

Berlin, S. et al. (2016) A family of photoswitchable NMDA receptors. eLife 5, Levitz, J. et al. (2013) Optical control of metabotropic glutamate receptors. Nature Neuroscience 16, 507-516

Tochitsky, I. et al. (2012) Optochemical control of genetically engineered neuronal 
nicotinic acetylcholine receptors. Nature Chemistry 4, 105-111

Lin, W.-C. et al. (2014) Engineering a Light-Regulated GABAA Receptor for Optical

Lin, W.-C. et al. (2015) A Comprehensive Optogenetic Pharmacology Toolkit for In Vivo Control of GABA(A) Receptors and Synaptic Inhibition. Neuron 88, 879-891 Donthamsetti, P. et al. (2017) Optical Control of Dopamine Receptors Using a Photoswitchable Tethered Inverse Agonist. J. Am. Chem. Soc. DOI: 10.1021/jacs.7b07659

Lemoine, D. et al. (2013) Optical control of an ion channel gate. Proceedings of the National Academy of Sciences 110, 20813-20818

Caporale, N. et al. (2009) LiGluR Restores Visual Responses in Rodent Models of Inherited Blindness. Molecular Therapy 19, 1212-1219 Levitz, J. et al. (2016) A Toolkit for Orthogonal and in vivo Optical Manipulation of Ionotropic Glutamate Receptors. Front. Mol. Neurosci. 9, 2 Broichhagen, J. et al. (2015) Orthogonal Optical Control of a G Protein-Coupled Receptor with a SNAP-Tethered Photochromic Ligand. ACS Cent. Sci. 1, 383-393 Levitz, J. et al. (2017) Dual optical control and mechanistic insights into photoswitchable group II and III metabotropic glutamate receptors. Proceedings of the National Academy of Sciences 114, E3546-E3554 Farrants, H. et al. (2018) SNAP-tagged nanobodies enable reversible optical control of a $\mathrm{G}$ protein-coupled receptor via a remotely tethered photoswitchable ligand. ACS Chem. Biol. DOI: 10.1021/acschembio.8b00628 Berry, M.H. et al. (2018) Restoration of patterned vision with an engineered photoactivatable G protein-coupled receptor. Nature Communications 2017, 1-

Tsai, Y.-H. et al. (2015) Selective, rapid and optically switchable regulation of protein function in live mammalian cells. Nature Chemistry 7, 554-561 Kang, J.-Y. et al. (2013) In Vivo expression of a light-activatable potassium channel using unnatural amino acids. Neuron 80, 358-370 Han, S. et al. (2017) Expanding the genetic code of Mus musculus. Nature Communications 8, 1-7 
with cellular specificity. Proceedings of the National Academy of Sciences 109, 4756-4761

$548 \quad 54$

549

$550 \quad 55$

551

55256

553

$554 \quad 57$

555

$556 \quad 58$

557

$558 \quad 59$

559

$560 \quad 60$

561

562

$563 \quad 61$

564

565

Gruber, T.D. et al. (2018) Cell-Specific Chemical Delivery Using a Selective Nitroreductase-Nitroaryl Pair. ACS Chem. Biol. 13, 2888-2896

Yang, Y. et al. (2015) Cell type-specific pharmacology of NMDA receptors using masked MK801. eLife 4, 9092

Chung, M.-K. et al. (2008) TRPV1 shows dynamic ionic selectivity during agonist stimulation. Nature Neuroscience 11, 555-564

Khakh, B.S. et al. (1999) Neuronal P2X transmitter-gated cation channels change their ion selectivity in seconds. Nature Neuroscience 2, 322-330

Binshtok, A.M. et al. (2007) Inhibition of nociceptors by TRPV1-mediated entry of impermeant sodium channel blockers. Nature 449, 607-610

Kim, H.Y. et al. (2010) Selectively targeting pain in the trigeminal system. Pain 150, 29-40

Roberson, D.P. et al. (2011) Targeting of sodium channel blockers into nociceptors to produce long-duration analgesia: a systematic study and review. British Journal of Pharmacology 164, 48-58

Banghart, M.R. et al. (2009) Photochromic Blockers of Voltage-Gated Potassium Channels. Angew. Chem. Int. Ed. Engl. 48, 9097-9101

Mourot, A. et al. (2012) Rapid optical control of nociception with an ion-channel photoswitch. Nature Methods 9, 396-402

Mourot, A. et al. (2017) Understanding and improving photo-control of ion channels in nociceptors with azobenzene photo-switches. British Journal of Pharmacology 175, 2296-2311

Kim, Y.S. et al. (2014) Central Terminal Sensitizationof TRPV1 by Descending Serotonergic Facilitation Modulates Chronic Pain. Neuron 81, 873-887

Tochitsky, I. et al. (2014) Restoring Visual Function to Blind Mice witha Photoswitch that Exploits Electrophysiological Remodeling of Retinal Ganglion Cells. Neuron 81, 800-813

Tochitsky, I. et al. (2016) How Azobenzene Photoswitches Restore Visual Responses to the Blind Retina. Neuron 92, 100-113

Mourot, A. et al. (2011) Tuning photochromic ion channel blockers. ACS Chem. 
Gomez, J.L. et al. (2017) Chemogenetics revealed: DREADD occupancy and activation via converted clozapine. Science 357, 503-507

58470 Thompson, K.J. et al. (2018) DREADD Agonist 21 Is an Effective Agonist for Muscarinic-Based DREADDs in Vitro and in Vivo. ACS Pharmacology \& Translational Science 1, 61-72

Magnus, C.J. et al. (2019) Ultrapotent chemogenetics for research and potential clinical applications. Science 364,

Dong, M. et al. (2017) Near-Infrared Photoswitching of Azobenzenes under Physiological Conditions. J. Am. Chem. Soc. 139, 13483-13486

Eldridge, M.A.G. et al. (2015) Chemogenetic disconnection of monkey orbitofrontal and rhinal cortex reversibly disrupts reward value. Nature Neuroscience 19, 37-39

Raper, J. et al. (2017) Metabolism and Distribution of Clozapine-N-oxide: Implications for Nonhuman Primate Chemogenetics. ACS Chem. Neurosci. 8, 1570-1576

Weston, M. et al. (2019) Olanzapine: A potent agonist at the hM4D(Gi) DREADD amenable to clinical translation of chemogenetics. Sci Adv 5, eaaw1567 Chen, X. and Wu, Y.-W. (2016) Selective chemical labeling of proteins. Org. Biomol. Chem. 14, 5417-5439 
Azobenzene, chemical photoswitch that can be reversibly isomerized between an elongated

605

606

607

608

609

610

611

612

613

614

615

616

617

618

619

620

621

622

623

624

625

626

627

628

629

630

631

632 trans state and a twisted cis isomer with short (classically near-UV) and long (blue-green) wavelengths of light, respectively.

BOLT, bioorthogonal ligand tethering. Ligand is conjugated to an UAA through click-chemistry.

Bump-hole, strategy based on the enlargement of binding sites (holes) in proteins (initially enzymes) to make them selective to complementary "bumped" ligands.

Click chemistry, orthogonal bioconjugation reaction that is rapid, biocompatible and high yielding.

CM, cyclopropylmethyl carboxyl. Masking group cleaved selectively by PLE.

Cre/lox recombination, genetic manipulation based on an enzyme, Cre recombinase, and its recognition site, lox $\mathrm{P}$, used for tissue-specific gene expression.

DART, drugs acutely restricted by tethering. Method for capturing drugs at the cell surface using a HaloTag.

DREADDs, Designer Receptors Exclusively Activated by Designer Drugs. Engineered GPCRs that exclusively respond to synthetic ligands.

GPI anchor, glycolipid (Glycosylphosphatidylinositol) that can be attached to the C-terminus of a protein.

His-tag, tag made of 4 to 9 histidine residues (4 in the MAC technology) classically used for purification of recombinant proteins. 
633 LOV domain, light-oxygen voltage domain. Blue light sensor from algae, plants, bacteria and 634 funghi, used to control cellular responses with light.

635

636 MAC, metal complex-agonist conjugates. Bifunctional ligand containing a $\mathrm{Ni}^{2+}$-nitrilotriacetic 637 acid (Ni-NTA) moiety for selective coordination tethering to his-tagged receptors.

638

639 Maleimide, $1 \mathrm{H}$-pyrrole-2,5-dione. Cysteine-reactive chemical group.

640

NM, 2-nitro-N-methylimidazolyl. Masking group selectively unmasked with NTR.

642

643

NTR, Nitroreductase from E. Coli used for selective reduction of NM groups.

644

645

Opto-XR, chimeric photocontrollable receptor engineered using opsins and the intracellular 646 loops or N-terminal tail of mammalian GPCRs.

647

648

Orthogonal, which does not interfere with native biological processes.

649

650

PEG, polyethylene glycol. Flexible polymer that is highly water soluble.

651

652

PLE, porcine liver esterase. Exogenous enzyme that efficiently and selectively hydrolyses CM

653 ester substrates.

654

655

PORTL, photoswitchable orthogonal remotely tethered ligand. Photoswitchable ligand tethered to a protein or nanobody through SNAP- or CLIP-tag conjugation.

657

PSAM/PSEM, Synthetic protein (pharmacologically selective actuator module, PSAM) that is selectively activated by synthetic ligands (pharmacologically selective effector molecules, PSEMS).

661

PTL, photoswitchable tethered ligand. Thiol-reactive ligand incorporating a chemical photoswitch, that photosensitizes cysteine-substituted receptors and ion channels. 
665 QAQ, Quaternary-ammonium azobenzene quaternary-ammonium. Light-sensitive blocker of 666 voltage-gated potassium and sodium channels, used as a photoreversible local anesthetics.

667

668 shRNAs, short (or small) hairpin RNA used to silence gene expression.

669

670 SNAP-, CLIP- and Halo-tags, Protein-based self-labeling tags, catalyzing the formation of a 671 specific, covalent bond between a labeling molecule and a tag-fused protein of interest.

672

673 Tethered, covalently (irreversibly) anchored.

674

675 Tet-on/off system, tetracycline (Tet) approach for precise and reversible spatiotemporal 676 control of gene expression.

677

678 Thiol, side chain of the amino acid cysteine, which imparts reactivity to maleimides for ligand 679 tethering.

680

681 UAA, unnatural amino acid. Synthetic amino acid which can be incorporated in proteins using 682 the Amber stop codon technology. 
Figure 1-Cell-specific neuropharmacology strategies. A. Cell-specific pharmacology concept.

686

687

688

689

690

691

692

693

694

695 A drug (green) is delivered to the whole organism but targets only specific types of neurons in the brain. The approach allows to evaluate the neurophysiological and behavioral consequences of the manipulation of receptors in discrete circuits of the brain. B. Bump-hole strategy. Top: the ligand (agonist or antagonist, green) acts on wild-type proteins. (Bottom left) The engineered protein contains a "hole" in the binding pocket, while the synthetic ligand (purple) contains a corresponding "bump". The mutant protein is non-orthogonal because it remains sensitive to the endogenous ligand (green). The orthogonal ligand acts specifically and exclusively on the engineered protein. (Bottom right) Both the modified protein and the synthetic ligand are orthogonal. C. Leftward shift in the concentration-response curve for the synthetic ligand (purple) compared to the natural agonist or antagonist (green). D. Tetheredligand approaches developed for G-protein coupled receptors (GPCRs), ligand-gated (LGICS) and voltage-gated ion channels (VGIC). (Left) The ligand is either embedded in the cell membrane (membrane-tethered) or tethered to the receptor itself (receptor-tethered). E. Intracellular delivery approaches. The drug is inactive in the extracellular space, and gets active only after it has entered targeted cells. Color coding throughout figures A-E: native proteins are shown in light grey and engineered ones in dark grey.

Figure 2-The receptor-ligand pair approach. A. Designer Receptors Exclusively Activated by Designer Drugs (DREADDs). DREADDs are orthologous receptor-ligand pairs made of a modified human muscarinic receptor ( $\mathrm{hM})$, with mutations in transmembrane domains (orange), that is insensitive to its natural agonist acetylcholine (ACh), but is exclusively activated by a synthetic ligand (e.g. clozapine-N-oxide, CNO). B. The Pharmacologically Selective Actuator Module/Effector Molecules (PSAM/PSEM) strategy: PSAM is an orthogonal, engineered ligand binding domain (LBD) of the homopentameric $\alpha 7-n A C h R s$ that is solely activated by PSEM (and not ACh). Different ion pore domains (IPDs) can be spliced on the PSAM allowing calcium, cation or chloride permeation. C. The Opto-XR approach: Opsin-GPCR chimeras are made of the intracellular domains of mammalian GPCRs (such as $\beta 2$ - and $\alpha 1$ adrenergic receptors, grey) swapped on the transmembrane (TM) domain of mammalian opsin (e.g. rhodopsin, blue). Opto-XRs are not sensitive to endogenous ligands (e.g. 
norepinephrine, NE). They contain a retinal chromophore (blue) and enable the optical control of intracellular signaling transduction. D. Zolpidem (pink) potentiates GABA signaling by binding to $\mathrm{GABA}_{\mathrm{A}} \mathrm{Rs}$ that contain the $\gamma 2$ subunit. Substitution of phenylalanine (F) 77 by isoleucine (I) on $\gamma 2$ induces a loss of response to zolpidem. E. Mutation of the leucine residue in position 9' (L9'), for instance to Alanine (A), leads to a "hypersensitive" nAChR that is activated with subthreshold concentrations of the agonist nicotine.

Figure 3 - The tethered ligand approach. A. t-Toxins and t-Peptides are genetically-encoded ligands permanently tethered to the cell surface through either a glycosylphosphatidylinositol (GPI) anchor (depicted here) or a transmembrane domain (TM). B. Lumitoxin are chimeric proteins composed of a TM, a light-oxygen-voltage (LOV) domain, a linker and a toxin (green). In darkness, Lumitoxin blocks endogenous potassium channels at the cell surface, while illumination with blue light unfolds LOV and relieves blockade. C. The Drug Acutely Restricted by Tethering (DART) strategy is based on the expression of a TM anchor linked to a specific self-labeling protein tag (e.g. HaloTag), allowing the capture of a specific ligand to the cell surface. The ligand is composed of a HaloTag Ligand (HTL), a flexible linker (poly-ethylene glycol, PEG) and a ligand (green). Conjugation results in a 100 -fold increased concentration of the ligand at the cell surface. D. Specific binding of a Metal complexe-Agonist Conjugate (MAC) to a His-Tagged GPCR, through coordination between the $\mathrm{Ni}^{2+}$-nitrilotriacetic acid (Ni-NTA) group of the ligand and the His-Tag. E. Photoswichable tethered ligands (PTLs) are composed of a cysteine reactive group (maleimide, grey), a photosensitive azobenzene core (orange), and a ligand (green). PTLs covalently attach to an engineered receptor that contains a single cysteine substitution, near the ligand binding site, thereby affording reversible photocontrol. F. Photoswitchable orthogonal remotely tethered ligands (PORTLs) are composed of a ligand, a photoswitchable azobenzene molecule, a flexible linker and a benzylguanine (BG) or benzylcytosine (BC) group for conjugation to SNAP- or CLIP-Tags, respectively.

Figure 4: Intracellular delivery approaches. A. The enzyme-prodrug pair approach relies on the use of a masked prodrug, and an exogenous enzyme that coverts the prodrug into an active drug. B. The facilitated diffusion approach uses large ion channels such as TRPV1 or P2X receptors for the selective entry of membrane-impermeant drugs. Here the drug is photocontrollable, enabling on and off action at the target protein with two distinct 
wavelengths of light.

750 Box 1: Bioconjugation technologies.

751 Bioconjugation reagents are used to link together a small chemical molecule (e.g. a ligand) 752 and a protein of interest (POI). Chemically tagging a protein with low toxicity and high 753 specificity in a complex cellular environment is a challenge. It requires genetic modification of 754 the POI, in order to incorporate a reactive group that will serve as a biorthogonal handle for 755 conjugation. Multiple strategies exist [76]. The smallest and least disruptive genetic 756 modification is the incorporation of a cysteine amino acid on the protein surface through site757 directed mutagenesis. Cysteines contain a thiol group that reacts efficiently, rapidly (minutes) 758 and with high selectivity with maleimide groups (Figure I) to form stable, covalent adducts 759 [76]. Cysteine has become the primary choice for site-specific modification of membrane 760 proteins because it is relatively low abundant, often engaged in disulfide bridges, and highly nucleophilic at neural $\mathrm{pH}$ [21]. Importantly, due the strong reductive environment of the cytoplasm, cysteine-maleimide conjugation chemistry is restricted to extracellularlyaccessible sites on membrane proteins [21]. In addition, because cysteines are naturally present on many endogenous proteins, novel bioconjugation techniques that work inside cells and that are fully bio-orthogonal have been developed. This includes the use of unnatural amino acids (UAA) that contain a double (alkene) or triple bond (alkyne) for bioconjugation with tetrazine-containing ligands through click chemistry [50] (Figure I). Click-chemistry is extremely popular for protein bioconjugation because it relies on chemical groups that are highly selective toward each other -yet remain inert otherwise-, exhibits fast reaction kinetics in aqueous media (minutes) and produces adducts that are very stable [76]. However, UAAs must be incorporated into proteins through Amber codon suppression technology, which remains challenging in vivo [52]. The other approaches for orthogonal labeling rely on larger modifications of the POI, such as the incorporation of polypeptide tags. For instance, metal chelation methods using poly-histidine tags (His-tag), which are classically used for protein purification, have been used for non-covalent labeling with Ni-NTA ligands [31]. His-tags are small (4-9 residues), conferring minimal disturbance to the protein, and label probes with high efficiency and selectivity. Nevertheless, labeling is reversible and $\mathrm{Ni}$ is toxic to cells, hampering in vivo use [76]. Finally, self-labeling domains such as SNAP-, CLIP- or HALO-tags use enzyme- 
779 catalyzed reactions for irreversible conjugation of ligands to POI in live cells. The reaction is 780 highly biorthogonal, rapid, irreversible and works intracellularly with low concentration of 781 substrate (nanomolar range) [76], but requires fusion of the POI with a large protein domain $782(>20 \mathrm{kDa})$ at the $\mathrm{N}$ - or $\mathrm{C}$-terminus, which either is prohibited (as with nAChRs or GABA $A_{A} R s$ for 783 instance) or may affect POI function.

784

785 Box1 Figure I. Representative reactive groups for protein-ligand bioconjugation.

786

787

788 


\section{Highlights}

Chemogenetic technologies that combine the speed of pharmacology with the cellular precision of genetics are emerging, enabling acute control of neuronal receptors with circuit specificity.

Targeting drugs to specific neuronal types usually requires genetic manipulation of either the target protein or the target cell.

In vivo implementation of these technologies allows unprecedented control brain of circuits at the molecular level, and help unambiguously link the activity of specific receptors to behavioral functions. 


\section{Outstanding questions box}

Is multiplexing possible? Only some of the methods described here allow for multiplexed interrogation across cell- (DREADDs, PSAM, DART) and receptor-types (PORTL). Notably, CLIPmGluR2 and SNAP-mGluR7 expressed in the same cell could be labeled and manipulated with orthogonal reactivity and wavelengths, respectively [41]. Nevertheless, novel approaches for concurrent delivery of two or more drugs to distinct cellular populations are needed.

Can DART be made photo-reversible? One current limitation of the DART technology is its slow reversal. In principle, adding a photo-isomerizable linker could help accelerate the off rate, as in the PORTL approach. However, DART and PORTL have two major differences: ligand/receptor stoichiometry and fixed vs. variable distance between the receptor and the anchor. It will be interesting to determine whether DART can be made photo-controllable.

Can fully bio-orthogonal groups be developed for tethered ligands? Most of the functional groups described in this review are not fully orthogonal, causing non-specific labeling in live cells. Others are too large (SNAP, CLIP...) and may affect protein function. Some groups are too lipophilic and have limited bioavailability. And most of them cannot pass the blood brain barrier and therefore have to be delivered locally into the brain. Hence, numerous challenges remain in bio-orthogonal chemistry in live cells. 


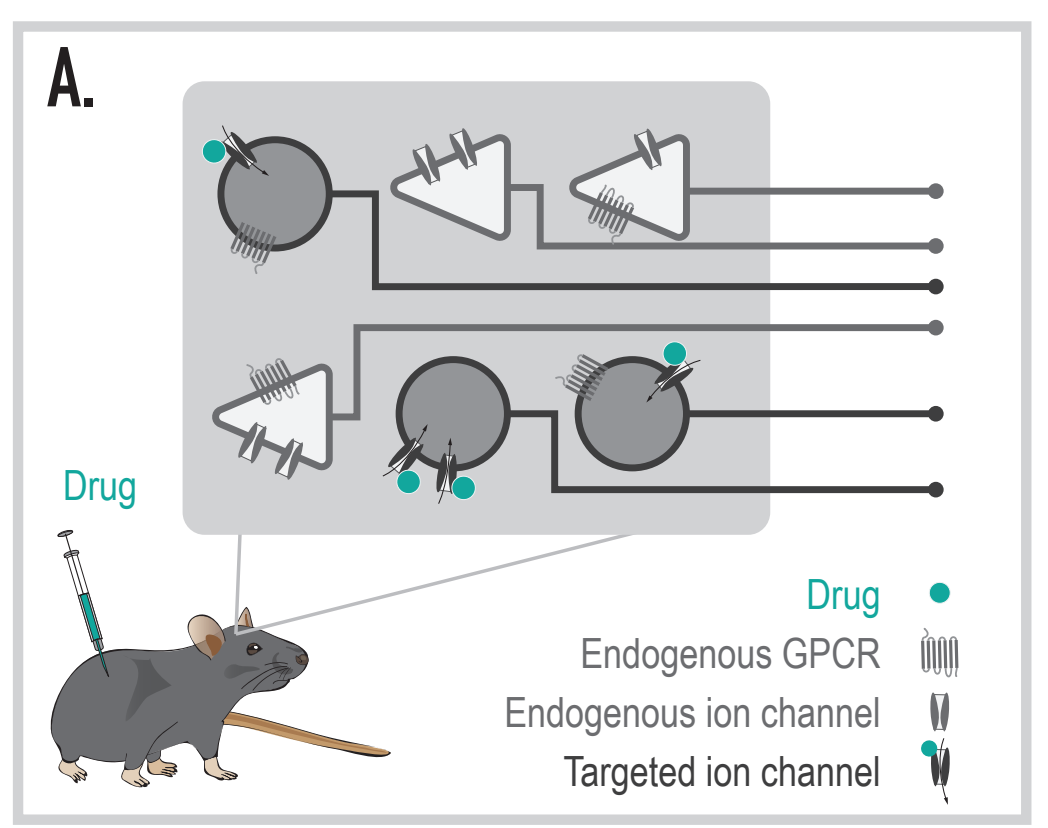

D. Membrane-tethered ligand

Ligand

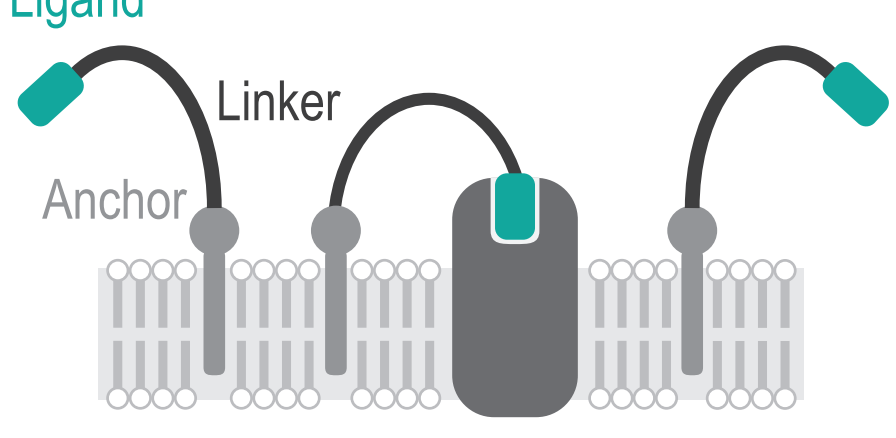

Native

GPCR/LGIC/VGIC
B.

\section{Bump-Hole}

Wild-type protein

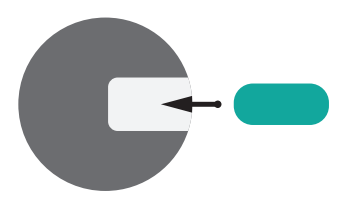

Agonist or antagonist

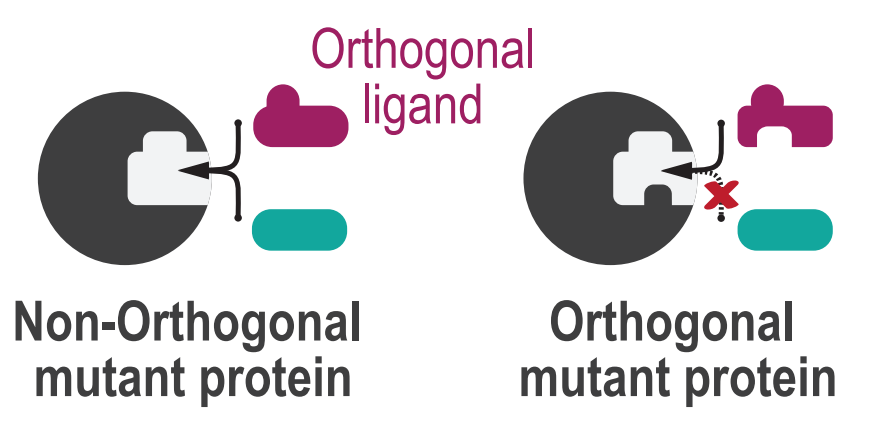

C.

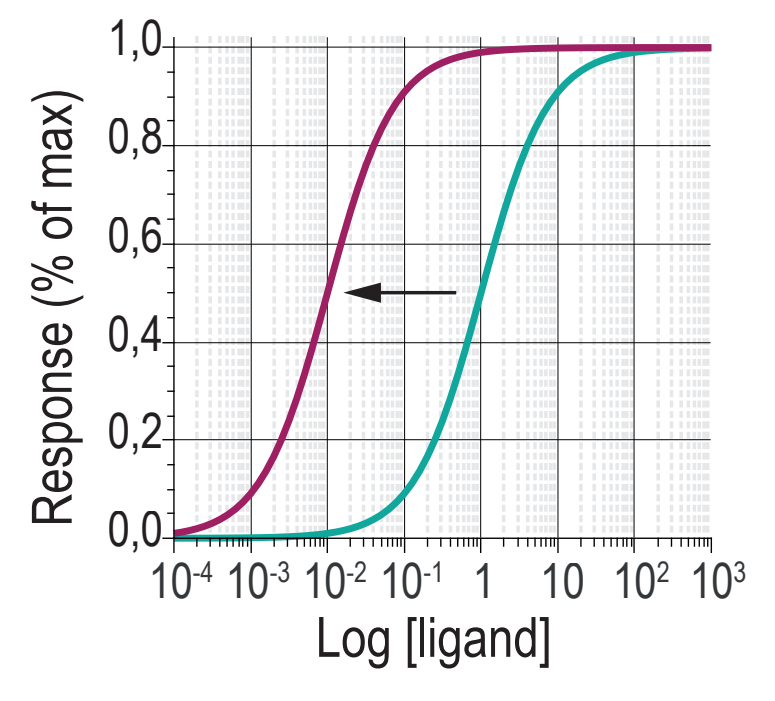

E. Intracellular delivery approaches

Receptor-tethered ligand Ligand

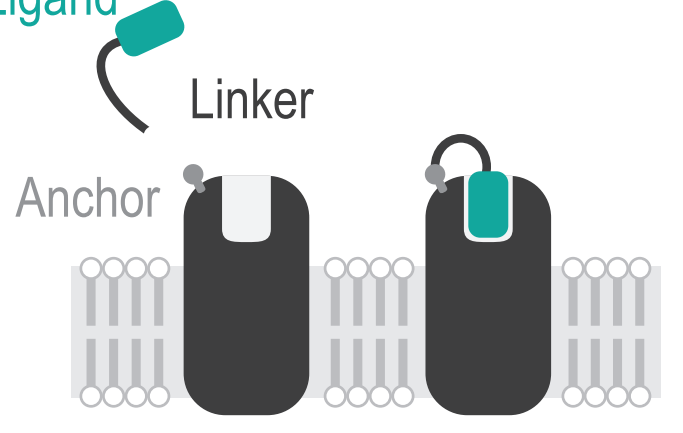

Engineered GPCR/LGIC/VGIC
Native Receptors/Channels

Inactive drug

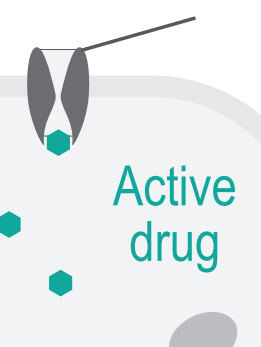

FIGURE 1 
A. DREADDS ACh
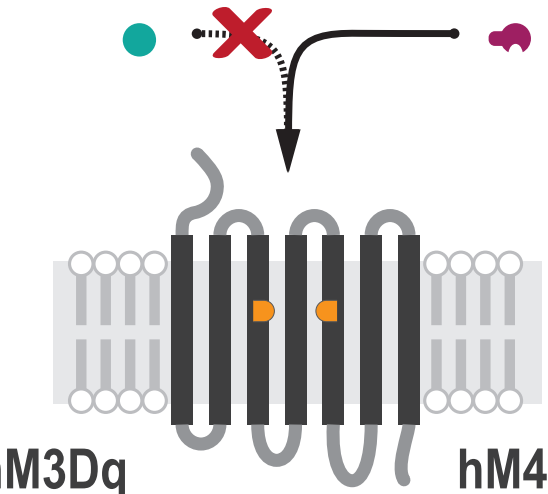

hM3Dq

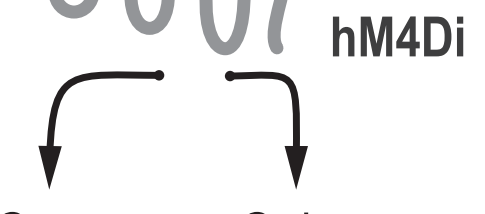

Gaq
CNO

Gail
B.

PSAM/PSEM

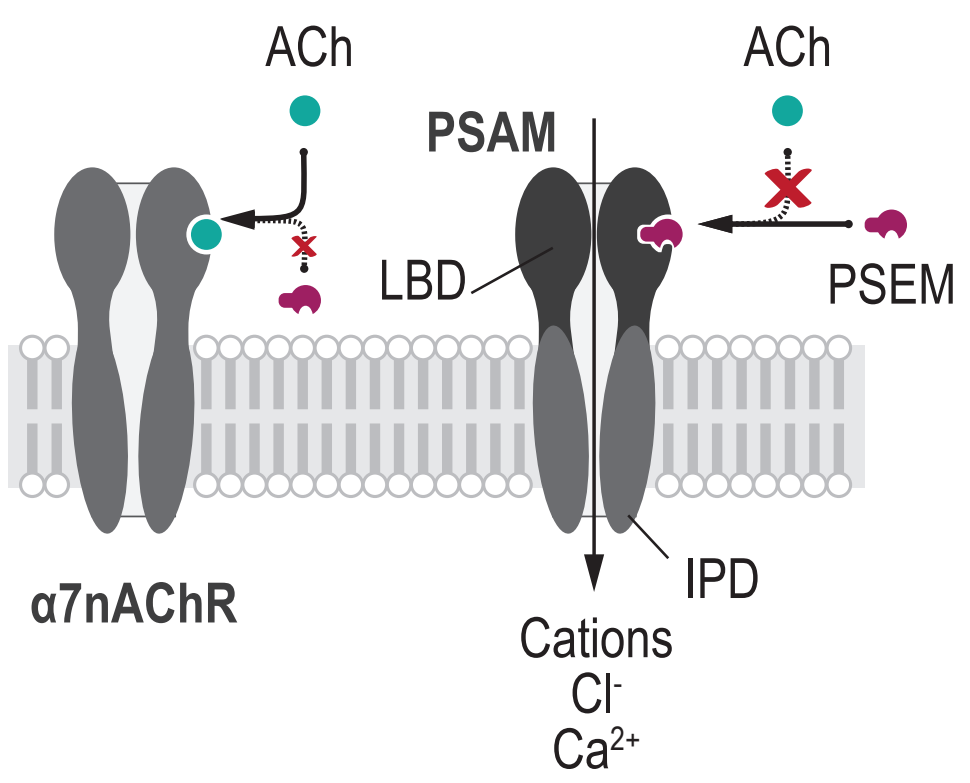

C. Opto-XRs

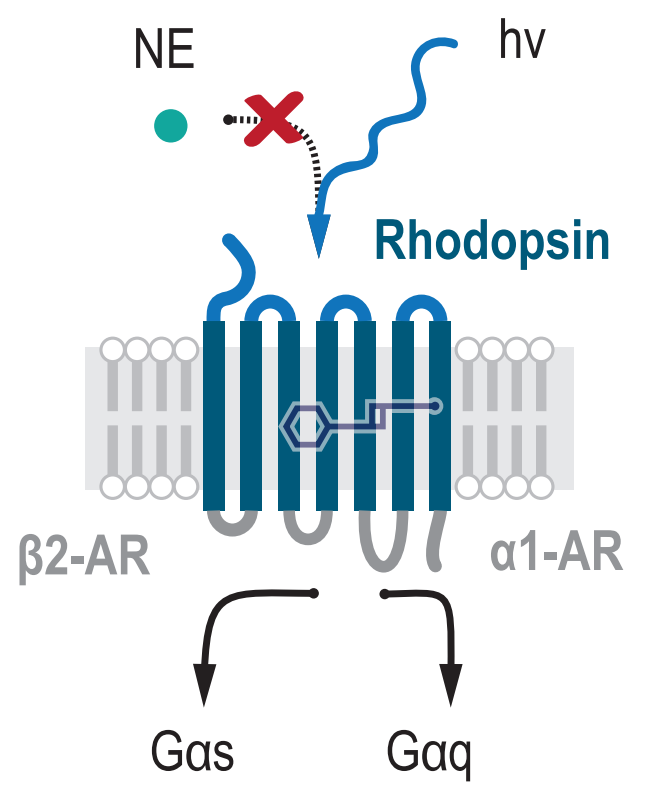

D. Zolpidem-insensitive $G A B A_{A}$ receptors
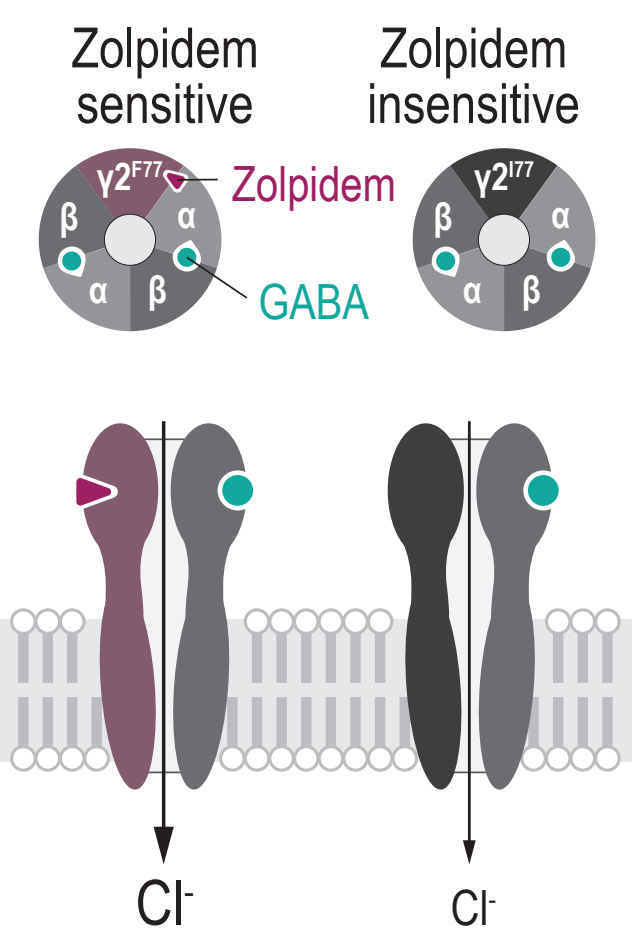

$Y 2^{F 77}$

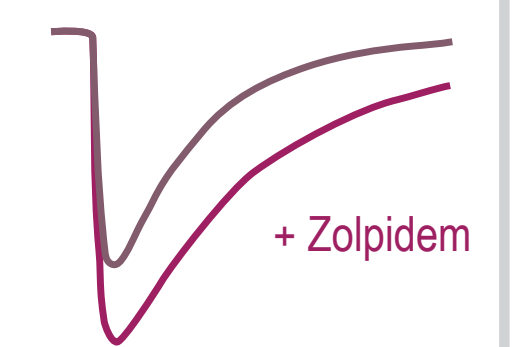

Y2 $2^{177}$

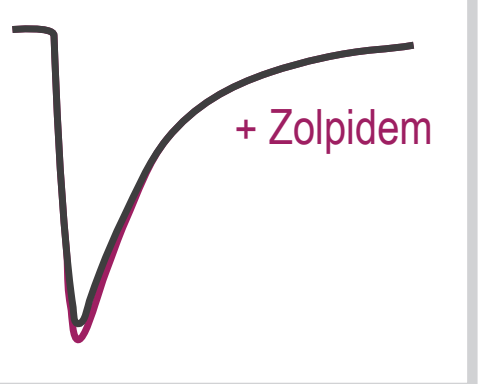

E.

\section{Gain of function nAChRs}

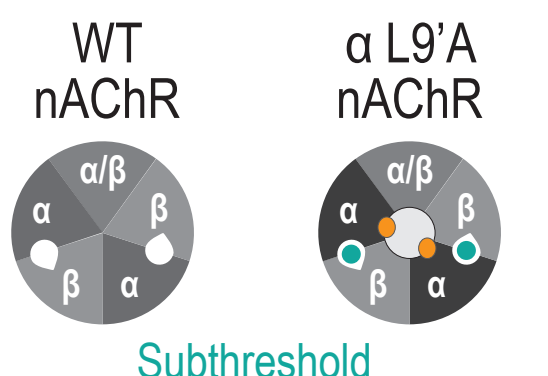

WT

Subthreshold Nicotine

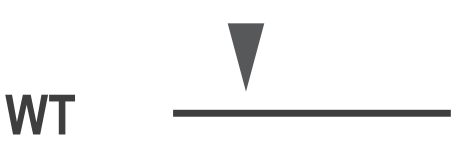

Subthreshold Nicotine
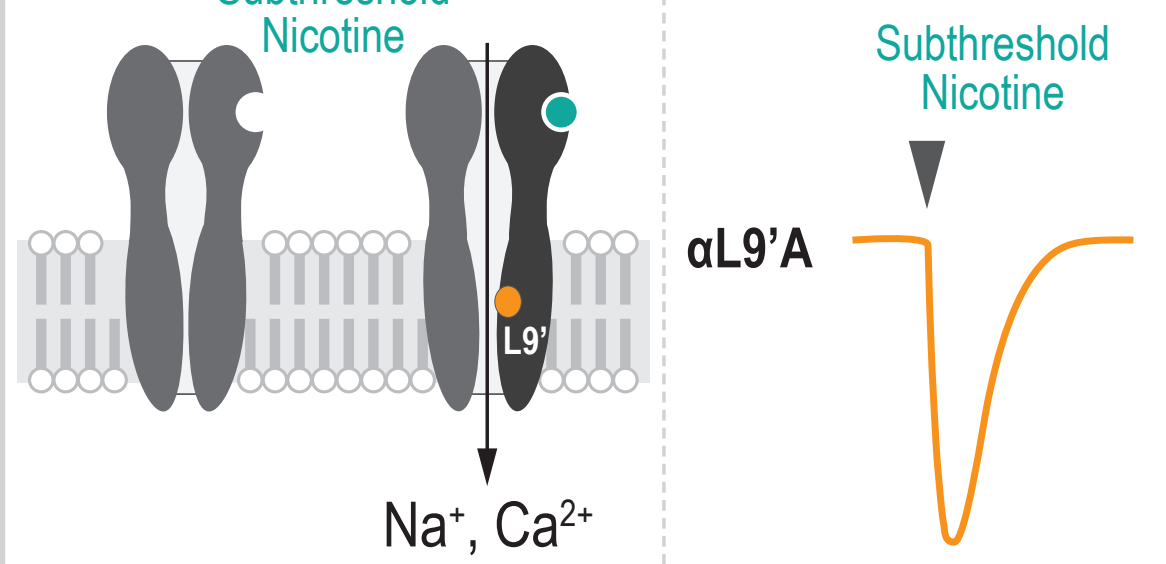
B.

\section{Lumitoxin}

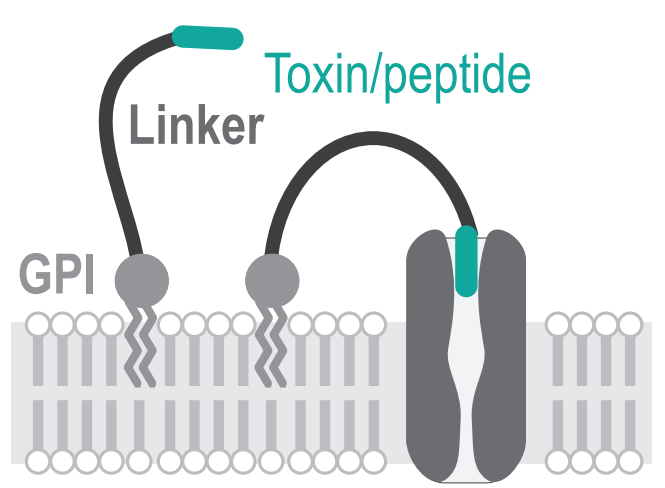

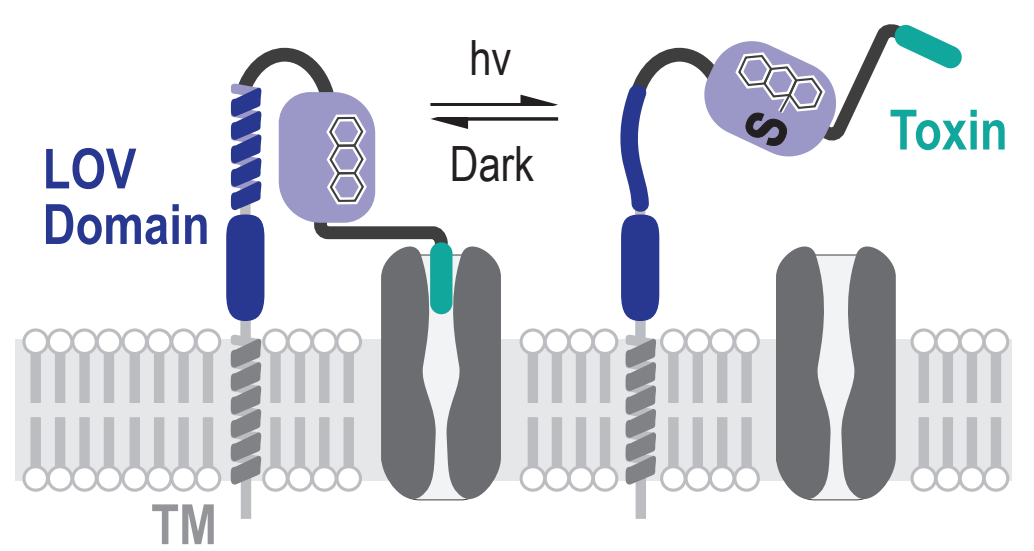

C. DART

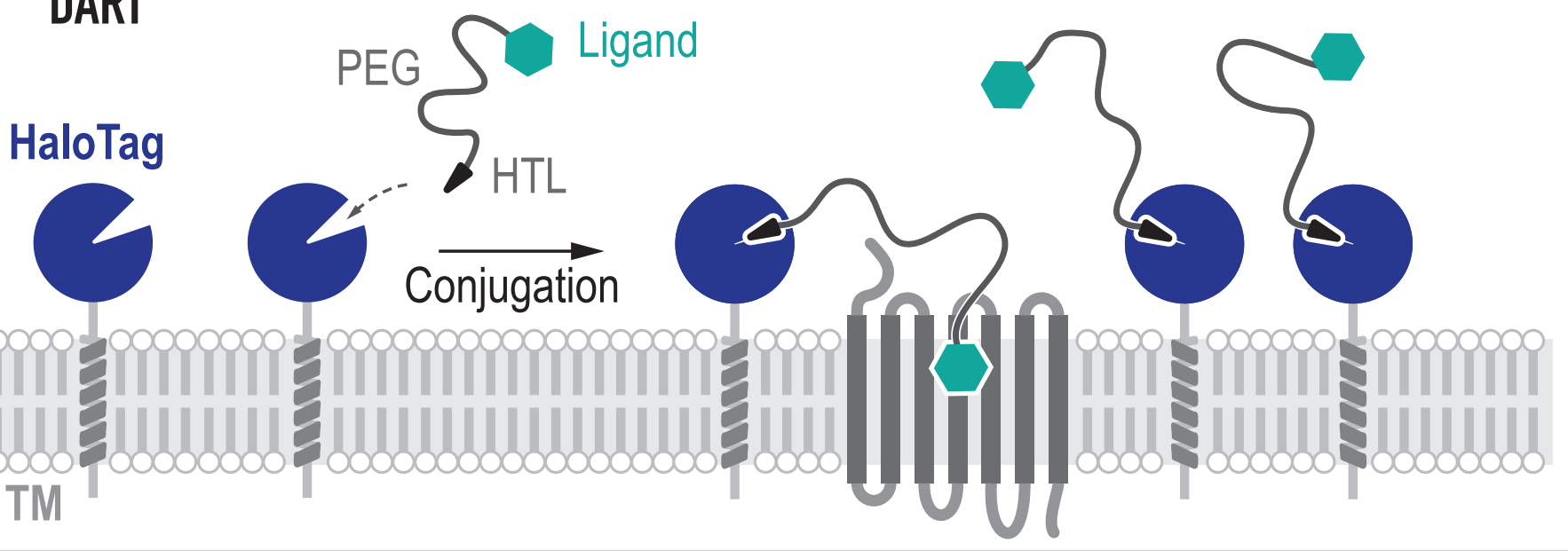

D. MAC

E. PTL
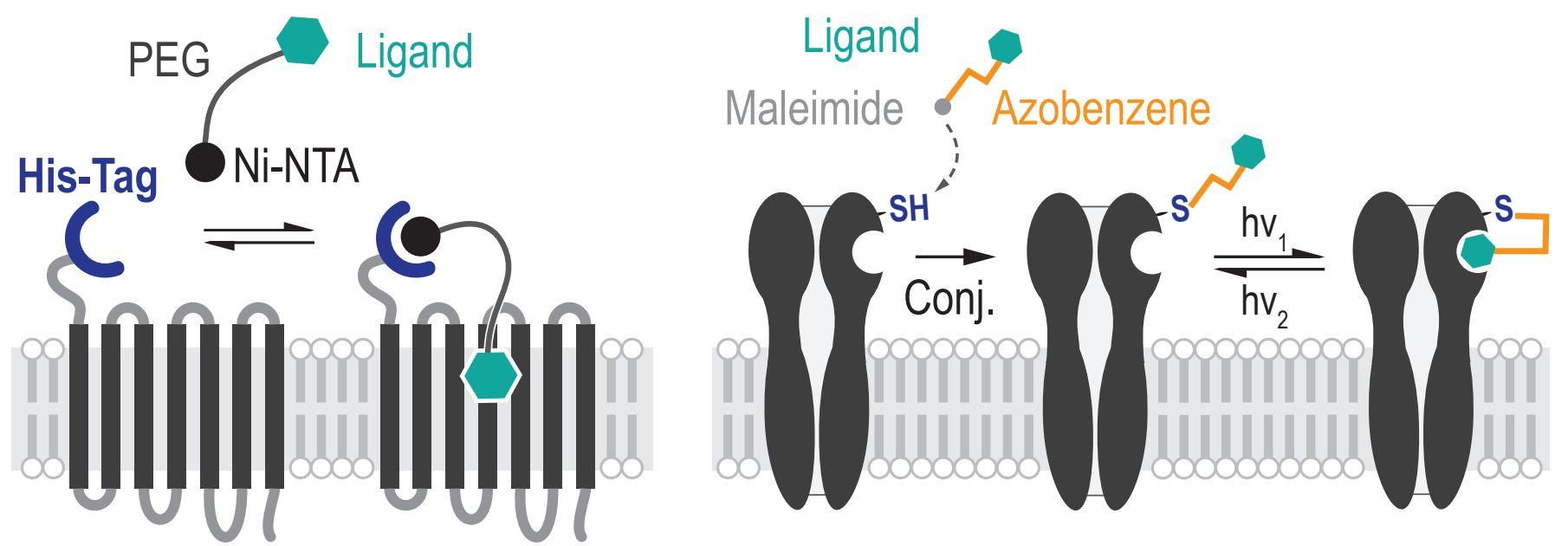

F. PORTL

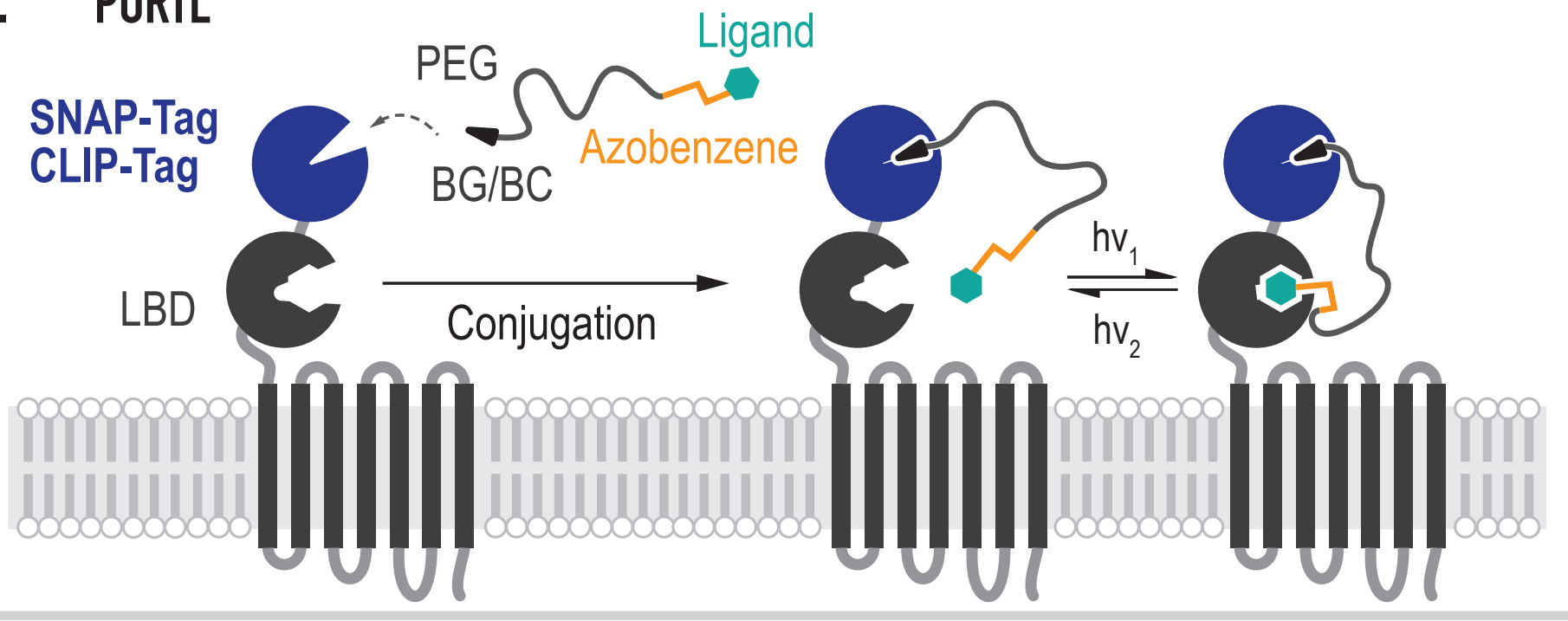


Figure 4

FIGURE 4

A. Enzyme-prodrug pair

B. Facilitated diffusion

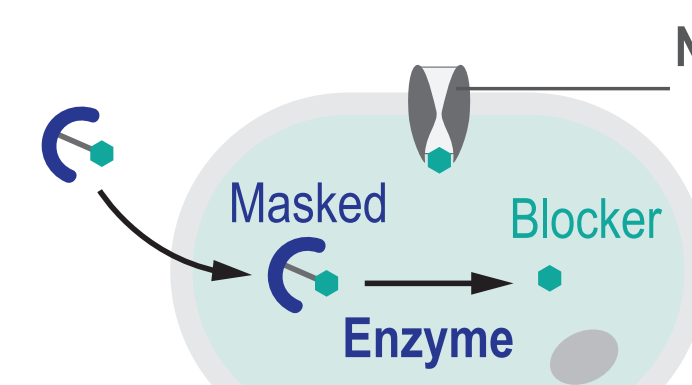

Native receptors/ channels

hiv

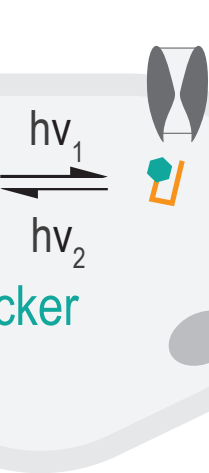

TRPV1 


\section{FIGURE - Box 1}

Engineered protein

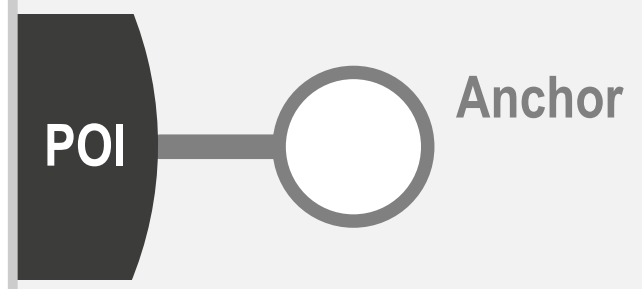

Thiol

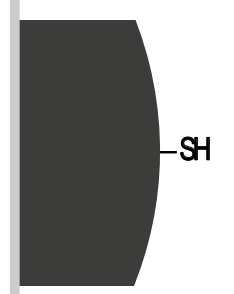

Alkyne (UAA)

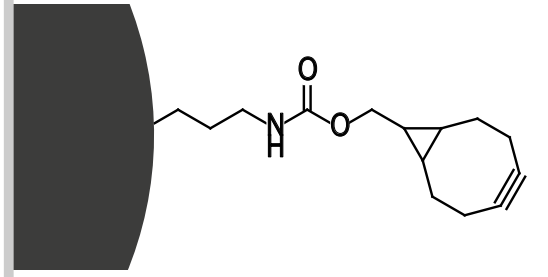

His-Tag

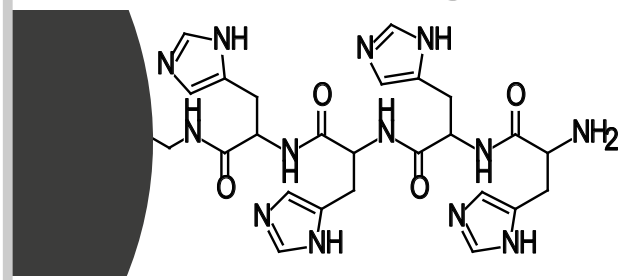

SNAP tag

(20 kDa)

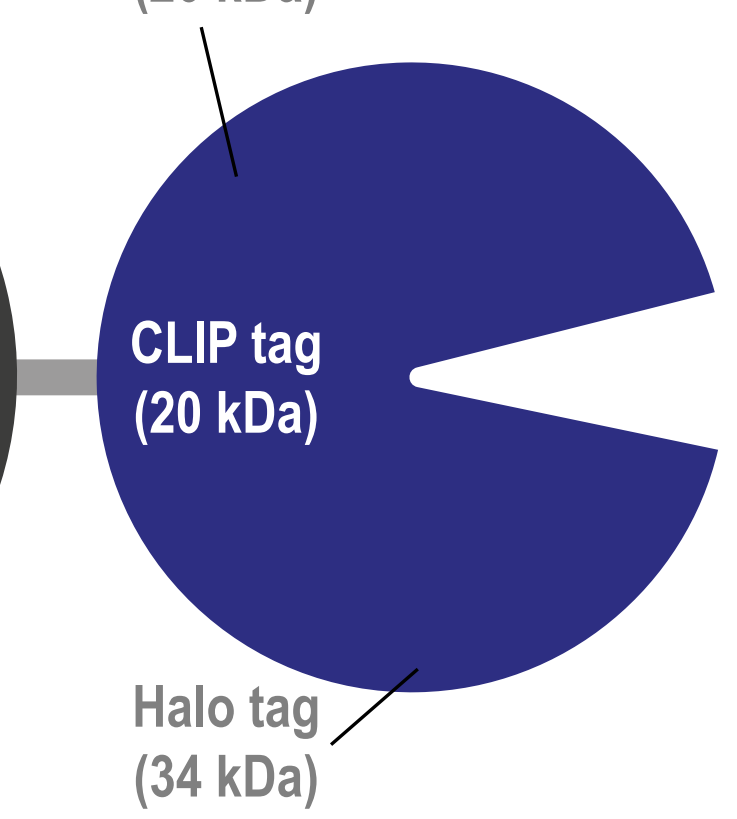

Synthetic molecule

Reactive

Group

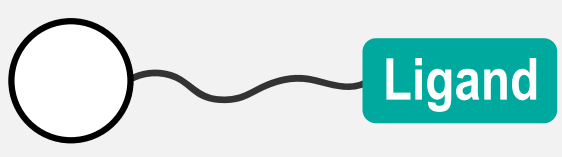

Maleimide

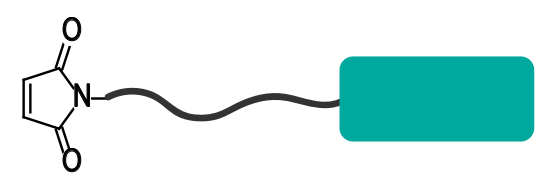

Tetrazine

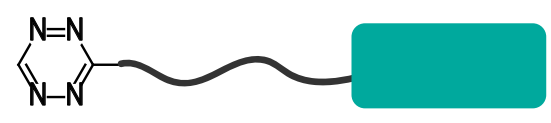

Ni-NTA

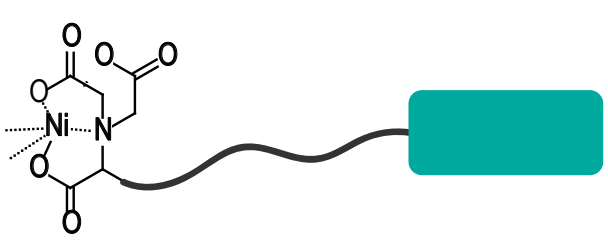

BG

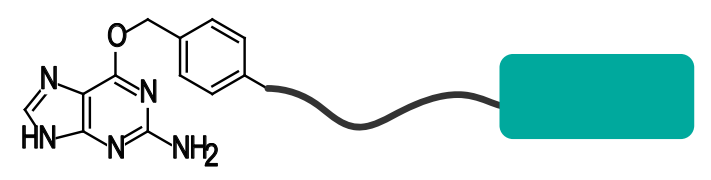

BC

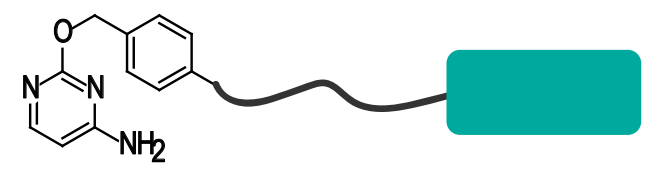

HTL (chloroalkane) 